\title{
Oral treatments for fungal infections of the skin of the foot (Review)
}

Bell-Syer SEM, Khan SM, Torgerson DJ

Bell-Syer SEM, Khan SM, Torgerson DJ.

Oral treatments for fungal infections of the skin of the foot.

Cochrane Database of Systematic Reviews 2012, Issue 10. Art. No.: CD003584.

DOI: 10.1002/14651858.CD003584.pub2.

www.cochranelibrary.com 
TABLE OF CONTENTS

HEADER 1

ABSTRACT

PLAIN LANGUAGE SUMMARY

BACKGROUND

OBJECTIVES

METHODS

RESULTS

Figure 1.

Figure 2.

DISCUSSION

AUTHORS' CONCLUSIONS

ACKNOWLEDGEMENTS

REFERENCES

CHARACTERISTICS OF STUDIES

DATA AND ANALYSES

Analysis 1.1. Comparison 1 Antifungal versus placebo, Outcome 1 Cured (terbinafine $250 \mathrm{mg}$ /day versus placebo).

Analysis 1.2. Comparison 1 Antifungal versus placebo, Outcome 2 Cured (itraconazole $400 \mathrm{mg}$ /day versus placebo).

Analysis 2.1. Comparison 2 Different types of antifungals, Outcome 1 Cured (terbinafine $250 \mathrm{mg} /$ day versus itraconazole 100 $\mathrm{mg} /$ day).

Analysis 2.2. Comparison 2 Different types of antifungals, Outcome 2 Cured (itraconazole $100 \mathrm{mg} / \mathrm{day}$ versus fluconazole 50 $\mathrm{mg} /$ day).

Analysis 2.3. Comparison 2 Different types of antifungals, Outcome 3 Cured (fluconazole $50 \mathrm{mg} /$ day versus ketoconazole 200 $\mathrm{mg} /$ day).

Analysis 2.4. Comparison 2 Different types of antifungals, Outcome 4 Cured (ketaconazole $200 \mathrm{mg} /$ day versus griseofulvin 1000 $\mathrm{mg} /$ day).

Analysis 2.5. Comparison 2 Different types of antifungals, Outcome 5 Cured (terbinafine $250 \mathrm{mg}$ versus griseofulvin $500 \mathrm{mg}$ ). ..

Analysis 2.6. Comparison 2 Different types of antifungals, Outcome 6 Cured (fluconazole $150 \mathrm{mg} /$ week versus fluconazole 50 $\mathrm{mg} /$ day).

Analysis 2.7. Comparison 2 Different types of antifungals, Outcome 7 Cured (terbinafine $250 \mathrm{mg} / 2$ weeks versus terbinafine 250 $\mathrm{mg} / 4$ weeks).

Analysis 3.1. Comparison 3 Presentation of tinea pedis, Outcome 1 Plantar tinea pedis.

Analysis 3.2. Comparison 3 Presentation of tinea pedis, Outcome 2 Mixed distribution of tinea pedis.

Analysis 4.1. Comparison 4 Adverse events, Outcome 1 Summary of adverse events reported for trials of tinea pedis. APPENDICES

FEEDBACK

WHAT'S NEW

HISTORY

CONTRIBUTIONS OF AUTHORS

DECLARATIONS OF INTEREST

SOURCES OF SUPPORT

DIFFERENCES BETWEEN PROTOCOL AND REVIEW

NOTES

INDEX TERMS 
[Intervention Review]

\title{
Oral treatments for fungal infections of the skin of the foot
}

\author{
Sally EM Bell-Syer ${ }^{1}$, Sameena M Khan ${ }^{1}$, David J Torgerson ${ }^{1}$
}

1Department of Health Sciences, University of York, York, UK

Contact address: Sally EM Bell-Syer, Department of Health Sciences, University of York, Area 2 Seebohm Rowntree Building, Heslington, York, North Yorkshire, YO10 5DD, UK. sally.bell-syer@york.ac.uk.

Editorial group: Cochrane Skin Group.

Publication status and date: Stable (no update expected for reasons given in 'What's new'), published in Issue 3, 2015.

Citation: Bell-Syer SEM, Khan SM, Torgerson DJ. Oral treatments for fungal infections of the skin of the foot. Cochrane Database of Systematic Reviews 2012, Issue 10. Art. No.: CD003584. DOI: 10.1002/14651858.CD003584.pub2.

Copyright @ 2015 The Cochrane Collaboration. Published by John Wiley \& Sons, Ltd.

\section{A B S T R A C T}

\section{Background}

About $15 \%$ of the world population have fungal infections of the feet (tinea pedis or athlete's foot). There are many clinical presentations of tinea pedis, and most commonly, tinea pedis is seen between the toes (interdigital) and on the soles, heels, and sides of the foot (plantar). Plantar tinea pedis is known as moccasin foot. Once acquired, the infection can spread to other sites including the nails, which can be a source of re-infection. Oral therapy is usually used for chronic conditions or when topical treatment has failed.

\section{Objectives}

To assess the effects of oral treatments for fungal infections of the skin of the foot (tinea pedis).

\section{Search methods}

For this update we searched the following databases to July 2012: the Cochrane Skin Group Specialised Register, CENTRAL in The Cochrane Library, MEDLINE (from 1946), EMBASE (from 1974), and CINAHL (from 1981). We checked the bibliographies of retrieved trials for further references to relevant trials, and we searched online trials registers.

\section{Selection criteria}

Randomised controlled trials of oral treatments in participants who have a clinically diagnosed tinea pedis, confirmed by microscopy and growth of dermatophytes (fungi) in culture.

\section{Data collection and analysis}

Two review authors independently undertook study selection, 'Risk of bias' assessment, and data extraction.

\section{Main results}

We included 15 trials, involving 1438 participants. The 2 trials (71 participants) comparing terbinafine and griseofulvin produced a pooled risk ratio (RR) of 2.26 (95\% confidence interval $(\mathrm{Cl}) 1.49$ to 3.44 ) in favour of terbinafine's ability to cure infection. No significant difference was detected between terbinafine and itraconazole, fluconazole and itraconazole, fluconazole and ketoconazole, or between griseofulvin and ketoconazole, although the trials were generally small. Two trials showed that terbinafine and itraconazole were effective compared with placebo: terbinafine (31 participants, $\mathrm{RR} 24.54,95 \% \mathrm{Cl} 1.57$ to 384.32 ) and itraconazole ( 72 participants, $\mathrm{RR} 6.67,95 \% \mathrm{Cl} 2.17$ to 20.48 ). All drugs reported adverse effects, with gastrointestinal effects most commonly reported. Ten of the trials were published over 15 years ago, and this is reflected by the poor reporting of information from which to make a clear 'Risk of bias' assessment. Only one trial was at low risk of bias overall. The majority of the remaining trials were judged as 'unclear' risk of bias because of the lack of clear statements with respect to methods of generating the randomisation sequence and allocation concealment. More trials achieved blinding of participants and personnel than blinding of the outcome assessors, which was again poorly reported. 


\section{Authors' conclusions}

The evidence suggests that terbinafine is more effective than griseofulvin, and terbinafine and itraconazole are more effective than no treatment. In order to produce more reliable data, a rigorous evaluation of different drug therapies needs to be undertaken with larger sample sizes to ensure they are large enough to show any real difference when two treatments are being compared. It is also important to continue to follow up and collect data, preferably for six months after the end of the intervention period, to establish whether or not the infection recurred.

\section{PLAIN LANGUAGE SUMMARY}

\section{Oral antifungal drugs for treating athlete's foot (tinea pedis)}

Athlete's foot (tinea pedis) is a fungal infection of the feet that is easily spread and difficult to get rid of. This review compared different oral antifungal drugs (i.e. drugs taken by mouth), and it included 15 trials, involving 1438 participants. There are several different kinds of oral treatments, and the trials we found considered all the oral drugs used to treat athlete's foot. We found terbinafine and itraconazole to be more effective than placebo. And we found terbinafine to be more effective than griseofulvin. Griseofulvin is a treatment that was developed much earlier than the new treatments, such as terbinafine and itraconazole; these newer treatments tend to be most evaluated. Trials of other drugs were not large enough to show differences between them. All drugs had side-effects; gastrointestinal effects were the most common.

In future clinical trials, larger numbers of participants are needed to test different treatments in order to produce more reliable data. Also, future research should consider the costs of the different treatment approaches. 


\section{B A C K G R O U N D}

\section{Description of the condition}

\section{Biology}

Fungal infections of the foot are common in people of all ages and can either affect the skin (tinea pedis) or the toenails (onychomycosis). The tenacity and duration of the infection can differ depending on the site. The cause of the infection is most frequently a dermatophyte (fungus), which inhabits and destroys keratin (a protein found in the outer layer of the skin). Tinea pedis, which tends to be restricted to the horny epidermal layers of the skin, is commonly known as 'athlete's foot'. It is contracted from infected skin fragments from other humans and, in some cases, animals (Brooks 1996). There are several clinical forms of tinea pedis, which can be easily confused with other non-infectious skin conditions, such as the following:

- interdigital tinea pedis, which is macerated and scaly in appearance and found mainly between the toes;

- plantar type tinea pedis (moccasin foot), which is fine, powdery scaling on a background of redness covering the skin of the soles, heels, and sides of the foot; and

- vesicular (bullous) type, an acute inflammatory condition, characterised by the formation of vesicles, pustules, or blisters. This can mimic foot dermatitis of various causes.

The causative organisms (dermatophytes) are classified into three genera: Epidermophyton, Microsporum, and Trychophyton. For tinea pedis, the main agents are Trichophyton rubrum, Trichophyton interdigitale (mentagrophytes), and Epidermophyton floccosum. Roseeuw 1999 found Trichophyton rubrum and Trichophyton interdigitale (mentagrophytes) were the most common pathogens in his European survey.

\section{Prevalence}

Traditionally, prevalence studies of tinea pedis have been conducted in school children (English 1959; English 1961), sailors (Catterall 1975), and coal-miners (Gentles 1957). More recently, athletes and those frequenting public swimming baths or modernday leisure centres have been studied. Gentles 1973 examined a random sample of $10 \%$ of all bathers at a public swimming bath and found the overall prevalence of tinea pedis was $8.5 \%$. The prevalence was higher in adults (17\%) than in children (4\%). Auger 1993 investigated marathon runners and found a prevalence of $22 \%$, with higher prevalence rates reaching $42 \%$ in the older age group (over 46 years). There is often a discrepancy between the methods of diagnosing tinea pedis whether by symptom (clinical) or microbiological confirmation (culture). For example, Gentles 1957 found that $90 \%$ of the coal miners studied had abnormalities of the skin of the feet, but only $21 \%$ were proven to be infected. A recent study in Australia (Merlin 1999) found that the prevalence of culture-proven tinea pedis was $5 \%$ in children, increasing with age from $2 \%$ in 4 to 6 year-olds to $10 \%$ in 16 to 18 year-olds (Merlin 1999). The increase in popularity of water-based leisure facilities prompted Detandt 1995 to compare the level of dermatophyte contamination on the floors of traditional swimming pools and subtropical swimming complexes. This study found that the floors of subtropical swimming complexes are more highly-contaminated with dermatophytes than the floors of traditional swimming pools. The study concluded that this was due to large visitor numbers, long opening hours, the complexity of construction, and choice of materials.

There is a clear trend showing that tinea pedis increases in prevalence with age, and Auger 1993 reported that his survey of tinea pedis indicated that men are infected about four times as frequently as women. This trend was confirmed by the Achilles study (Roseeuw 1999), which found that nearly twice as many men as women had fungal infections.

\section{Description of the intervention}

Before the late 1950s, only topical drugs were available. Topical drugs are those that are applied as a cream, spray, or lotion on the surface of the skin. Griseofulvin, the first significant oral (drug taken by mouth) antifungal agent, became available in 1958, and there have been many advances since then (Gupta 1994a). Although widely-used, griseofulvin is only effective for dermatophyte infections, and it needs to be taken for long treatment periods. It is associated with relatively minor sideeffects.

The azole class of drugs, the broad spectrum antifungals, were developed next. However, the first azole, ketoconazole, has been associated with liver damage (although this appears to be an idiosyncratic reaction (Jones 1982)), and it is now less favoured as an oral therapy. The 1980 s saw the introduction of itraconazole and fluconazole, which were thought to have increased potency, decreased toxicity, and a wider spectrum of action than earlier azoles (Gupta 1994b). Azoles are fungistatic (inhibit fungal growth) and inhibit fungal cell development at a later stage. Terbinafine, an allylamine, was also introduced. This drug has a broad spectrum of antifungal activity and is fungicidal in its action, i.e. it destroys the fungal cell at a much earlier stage in its development than the azoles.

Another less recognised oral treatment is bovine lactoferrin. Bovine lactoferrin (formerly known as lactotransferrin) is an ironbinding glycoprotein found in the secretions of some glands. It can be extracted from cow's milk. Because there is an increase in concentrations of lactoferrin at sites of infection during the inflammatory response, it is thought that lactoferrin is able to keep the iron bound, thus, preventing its use for bacterial proliferation (Alderova 2008). Lactoferrin and lactoferricin have been shown to inhibit in vitro growth of Trichophyton mentagrophytes, which is a dermatophyte responsible for skin conditions such as tinea pedis and ringworm (Wakabayashi 2000).

\section{How the intervention might work}

The numerous antifungal products available to treat tinea pedis differ both in costs and length of treatment. They can be taken as tablets (oral) or applied to the skin (topical). Clinical trials have focused mostly on topical treatments; oral therapy is more usually reserved for topical treatment failures and chronic conditions. Oral antifungal therapies are only available on prescription whereas many topical treatments are available to purchase over-thecounter (OTC). Topical therapies have usually been the first-line treatment for tinea pedis. A systematic review by Hart 1999 examined all topical therapies for tinea pedis and found that there were no significant differences in effectiveness between individual allylamines or individual azoles. It found that topical allylamines, which are available only on prescription, cured slightly more 
infections of tinea pedis than topical azoles or undecanoic acid, both of which are available OTC. The Hart 1999 review concluded that for tinea pedis the initial line of treatment should be with azoles or undecanoic acid, and allylamines should be reserved for topical treatment failures. However, tinea pedis can be resistant to treatment (Brautigam 1995), and topical treatments can be messy to apply and rely on the person complying with the recommended regimen.

The ideal oral antifungal compound for the treatment of fungal infection should be fungicidal so that the treatment can be of short duration, should give high cure rates, minimise relapses, be easy for people to take, and have minimal adverse side-effects.

\section{Why it is important to do this review}

Tinea pedis is not a minor condition that will resolve if left alone or treated inadequately. Fungal infections are treated by dermatologists, general practitioners, and podiatrists. They are overwhelmed with large amounts of information, and a systematic review of the research evidence is needed. To date, the research evidence has not been systematically appraised and synthesised to answer the key questions set out below. This systematic review addressed the main research question as to whether or not there is an effective oral treatment for tinea pedis and, if so, which treatment is most effective. Further research questions were as follows:

- Is there an optimum treatment duration?

- Is there an optimum dosage?

- Which intervention has fewest side-effects?

- Does any one clinical type of tinea pedis respond better to a particular treatment?

\section{O B JECTIVES}

To assess the effects of oral treatments for fungal infections of the skin of the foot (tinea pedis).

\section{METHODS}

\section{Criteria for considering studies for this review}

\section{Types of studies}

Randomised controlled trials (RCTs) of oral treatments for tinea pedis.

\section{Types of participants}

People, of any age, who have a fungal infection of the skin of the foot (tinea pedis) that has been clinically diagnosed and confirmed by microscopy and growth of dermatophytes in culture.

\section{Types of interventions}

Any treatment administered orally that aims to treat the fungal infection.

\section{Types of outcome measures}

\section{Primary outcomes}

1. Mycological cure, as demonstrated by negative results on microscopy and no growth of dermatophyte in culture. This outcome is recognised as the most effective way of assessing if the fungal infection has been eradicated; evaluating the condition by its appearance alone is not reliable (Elewski 1996).

\section{Secondary outcomes}

1. Clinical assessment of signs, such as redness, scaling, pustules, and symptoms, such as itching, burning, and soreness.

2. Measurement of any recurrence of the condition after achieving a cure 12 weeks after the start of the intervention.

3. Side-effects of the treatments as measured by the frequency of reported adverse events.

4. Cosmetic acceptability of the end result to the participant, absence of itchiness, and discomfort.

5. Identification of the type of infecting dermatophytes at baseline and at final outcome assessment.

\section{Search methods for identification of studies}

We aimed to identify all relevant RCTs regardless of language or publication status (published, unpublished, in press, or in progress).

\section{Electronic searches}

For this update, we revised the search strategies for the five databases listed below, and we searched up to 24 July 2012:

- the Cochrane Skin Group Specialised Register using the search strategy in Appendix 1;

- the Cochrane Central Register of Controlled Trials (CENTRAL) in The Cochrane Library using the search strategy in Appendix 2;

- MEDLINE (from 1946) using the strategy in Appendix 3;

- EMBASE (from 1974) using the strategy in Appendix 4; and

- CINAHL via EBSCO (Cumulative Index to Nursing and Allied Health Literature, from 1981) using the strategy in Appendix 5.

\section{Trials registries}

We searched the following trials registries on 23 July 2012 using the search terms 'tinea pedis' and 'athletes foot':

- The metaRegister of Controlled Trials (www.controlledtrials.com).

- The US National Institutes of Health Ongoing Trials Register (www.clinicaltrials.gov).

- The Australian New Zealand Clinical Trials Registry (www.anzctr.org.au).

- The World Health Organization International Clinical Trials Registry platform (www.who.int/trialsearch).

- The EU Clinical Trials Register (https:// www.clinicaltrialsregister.eu/).

We have detailed the search activities we undertook for the original review but did not repeat for this update in Appendix 6 .

\section{Searching other resources}

We checked the reference lists of all retrieved trials for further references to relevant trials. We did not contact manufacturers again for this update because of time and resource constraints. 


\section{Data collection and analysis}

\section{Selection of studies}

Two review authors (SB-S, RH, or SK) independently assessed all citations and abstracts and categorised them into the following:

- clearly a RCT;

- possibly a RCT (abstract or title providing insufficient evidence to make a firm decision); or

- clearly not a RCT.

We obtained all papers that were clearly or possibly a RCT in full text and further assessed them against the inclusion criteria, with any discrepancies being resolved by discussion.

\section{Data extraction and management}

We extracted and summarised details of the eligible trials using a data extraction sheet. Two review authors (SB-S, RH, or SK) extracted data independently and resolved disagreements by discussion. Where data were missing from reports, we attempted to contact the study authors to obtain the missing information. We included trials published in duplicate once, but extracted the maximal amount of data. We extracted the following data:

- country of origin;

- type of tinea pedis;

- unit of investigation (per participant) - site or foot or participant;

- care setting;

- number of participants randomised to each trial arm;

- eligibility criteria and key baseline participant data;

- details of the treatment regimen received by each group;

- details of any co-interventions;

- primary and secondary outcome(s) (with definitions);

- outcome data for primary and secondary outcomes (by group);

- duration of follow-up;

- number of withdrawals (by group);

- adverse events; and

- source of funding for trial.

\section{Assessment of risk of bias in included studies}

Two review authors (SB-S and SK) independently assessed each included study using The Cochrane Collaboration's tool for assessing risk of bias (Higgins 2011). This tool addresses six specific domains, namely sequence generation, allocation concealment, blinding, incomplete outcome data, selective outcome reporting, and other issues (e.g. extreme baseline imbalance) (see Appendix 7 for details of the criteria on which the judgement was based). We completed a 'Risk of bias' table for each eligible study. We resolved disagreements about 'Risk of bias' assessment by discussion. Where possible, where a lack of reported information resulted in an unclear decision, we contacted trial authors for clarification.

We presented our assessment of the 'Risk of bias' findings using a 'Risk of bias' summary figure, which showed all of the judgements in a cross-tabulation of study by entry. This display of internal validity indicates the weight readers may give to the results of each study. We also aimed to present this assessment in the narrative of the review.
We classified trials as being at high risk of bias if they were rated 'high' for any one of three key criteria, i.e. randomisation sequence, allocation concealment, or blinded outcome assessment.

\section{Measures of treatment effect}

Where possible, we presented the outcome results for each trial with $95 \%$ confidence intervals $(\mathrm{Cl})$. We reported estimates for dichotomous outcomes as risk ratios (RR). We used the RR rather than odds ratio (OR) since ORs (when interpreted as RR) can give an inflated impression of the effect size when event rates are high, as is the case for many trials reporting healing of tinea pedis.

\section{Assessment of heterogeneity}

We considered trials that compared similar interventions for a meta-analysis. These trials were also subject to an assessment of statistical heterogeneity in order to decide whether to adopt a fixed-effect or random-effects model. A fixed-effect model is a mathematical model for combining the results of trials that assumes that the effect is truly constant in all the populations studied. Only variation within the study is taken to influence the uncertainty of results. A random-effects model is a mathematical model for combining the results of trials that allows for variation in the effect amongst the populations studied. Therefore, both withinstudy and between-study variations are included in the assessment of the uncertainty of results. Heterogeneity is caused by variability between trials in such areas as the type of participants, the length of treatment or follow up, dose or frequency of the intervention, quality of the trial, etc.

We assessed statistical heterogeneity using the $\mathrm{Chi}^{2}$ test (we considered a significance level of $\mathrm{P}<0.1$ to indicate heterogeneity) and the $\mathrm{I}^{2}$ statistic estimate (Higgins 2003). The $\mathrm{I}^{2}$ statistic estimate examines the percentage of total variation across trials due to heterogeneity rather than to chance. Values of $\mathrm{I}^{2}$ statistic over $50 \%$ indicate a high level of heterogeneity. In the absence of clinical heterogeneity and in the presence of statistical heterogeneity $\left(I^{2}\right.$ statistic over $50 \%$ ), we used a random-effects model. Where there was no clinical or statistical heterogeneity, we envisaged using a fixed-effect model.

\section{Data synthesis}

For each trial we calculated the cure rates (the primary outcome measure) at each outcome point from the reported mycological results. The longest available follow-up, within each trial, was generally used in summarising the overall effectiveness.

We combined trials using a narrative overview with meta-analyses of outcome data where appropriate (in Review Manager 5). The decision to include trials in a meta-analysis depended on the availability of treatment effect data and assessment of heterogeneity.

Individual trials with small sample sizes may not be able to estimate effects precisely. By combining the data from these trials a meta-analysis acquires the power to increase the precision of the estimate of effect.

\section{Subgroup analysis and investigation of heterogeneity}

We undertook a subgroup analysis of the clinical presentation of tinea pedis. We also investigated the sponsorship of trials by the pharmaceutical industry by noting all trials that had received 
sponsorship and whether the results of the study were in favour of the intervention manufactured by the sponsor. It is possible that publication bias exists by positive findings being preferably published by a pharmaceutical company (Begg 1989).

\section{RE S U L T S}

\section{Description of studies}

We identified 42 trials; 15 met the inclusion criteria for the review; 25 were excluded; 1 study is awaiting assessment pending full text retrieval. In addition, we identified one potentially relevant study from a clinical trials registry; we contacted the study investigators who informed us that data are the property of the sponsoring pharmaceutical company. We contacted the company, but did not receive a reply. We put the information we have on this study in the 'Characteristics of ongoing studies' tables.

\section{Included studies}

We identified 42 trials; 15 met the inclusion criteria for the review and evaluated 6 different treatments. All trials were in the English language. There were a total of 1438 participants in the included trials.

The US was the country of setting for three trials (Savin 1990a; Savin 1990b; Smith 2001); seven trials were conducted in Europe (DeKeyser 1994; Difonzo 1995; Fischbein 1992; Hay 1995; Nozickova 1998; Roberts 1987; Svejgaard 1998); and five trials were conducted in Asia (Hoharitanon 2005; Kim 1993; Voravutinon 1993; Widyanto 1993; Yamanchi 2000).

All 15 trials used adult participants, with 1 study being conducted in a HIV population (27 participants) (Smith 2001).

Elevan trials reported the clinical type of tinea pedis: 4 trials reported moccasin type tinea pedis; 3 trials, plantar type tinea pedis; and six trials reported either mixed presentations of tinea pedis along with tinea cruris and tinea corporis or simply reported 'tinea pedis' with no further information.

The sample size of trials ranged from 27 to 366 , and the duration of follow up ranged from 2 to 16 weeks.

This review evaluated six oral treatments: terbinafine, itraconazole, ketoconazole, fluconazole, griseofulvin, and bovine lactoferrin. Two trials compared active treatments (terbinafine, itraconazole) with placebo. One study compared different doses of the same drug (fluconazole); 1 study compared different brands of the same drug (itraconazole), and 11 trials evaluated head-to-head comparisons.

Four trials reported receiving funding or support from pharmaceutical companies (DeKeyser 1994 ; Savin 1990a ; Smith 2001; Svejgaard 1998). One study declared receiving medication from a pharmaceutical company (Roberts 1987); one study reported help from a pharmaceutical company, but did not specifically report funding (Hay 1995). One study had coauthors affiliated with a pharmaceutical company (Difonzo 1995). The pharmaceutical companies were Novartis (formerly Sandoz Pharmaceuticals) (terbinafine) and Janssen Pharmaceuticals, Inc. (itraconazole, ketoconazole). One study evaluating bovine lactoferrin, which is a cow's milk component, recruited employees from a Milk Company as participants (Yamanchi 2000).

\section{Excluded studies}

Twenty-five trials (27 citations) did not meet the inclusion criteria (see the 'Characteristics of excluded studies' tables). The main reasons for exclusion were as follows:

- Twelve did not present separate data for tinea pedis (Baldari 2000; Degreef 1987; Del Palacio 1993; Hay 1991; Jolly 1983; Lachapelle 1992; Schuller 1998; Stengel 1995; Tausch 1998; Van Hecke 1988; White 1991; Wishart 1994).

- Four were review articles (Bortolussi 2007; Bortolussi 2008; Humphreys 2004; Markova 2002).

- Three were not randomised trials (Decroix 2008; Gupta 1999; Yao 1999).

- Two reported data for systemic and topical therapy (Barnetson 1998; Lynfield 1974).

- Two did not perform microscopy and culture to obtain a diagnosis of fungal infection (Russell 1960; Won 1993).

- One reported topical therapy alone (Brugmans 1969).

- One reported insufficient data (Legendre 1980).

We contacted all authors of excluded trials with a request for further information. We received no response to enable any of these trials to be considered for inclusion in this review.

\section{Risk of bias in included studies}

Please see Figure 1 and Figure 2. 
Figure 1. 'Risk of bias' summary: review authors' judgements about each 'Risk of bias' item for each included study

\begin{tabular}{|c|c|c|c|c|c|c|c|c|}
\hline & 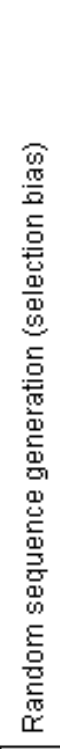 & 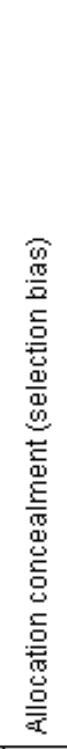 & 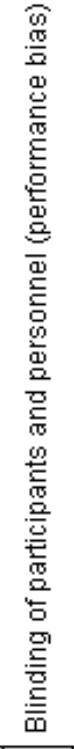 & 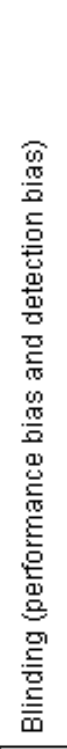 & 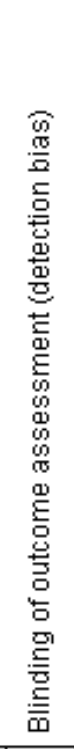 & 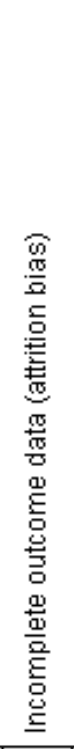 & 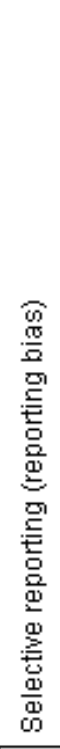 & 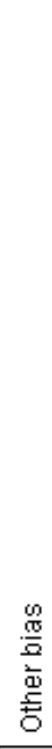 \\
\hline DeKeyser 1994 & 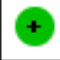 & + & + & + & + & $\odot$ & + & + \\
\hline Difonzo 1995 & $?$ & $?$ & + & $?$ & $?$ & $\odot$ & + & $\odot$ \\
\hline Fischbein 1992 & $?$ & $?$ & + & $?$ & $?$ & $\odot$ & + & $\odot$ \\
\hline Hay 1995 & $\Theta$ & $?$ & 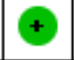 & $?$ & $?$ & $\odot$ & + & + \\
\hline Hoharitanon 2005 & $\odot$ & + & + & $?$ & $?$ & $\odot$ & + & + \\
\hline Kim 1993 & $?$ & $?$ & + & $?$ & $?$ & $\odot$ & + & $\odot$ \\
\hline Nozickova 1998 & $?$ & $?$ & $?$ & $?$ & $?$ & $\odot$ & + & $\odot$ \\
\hline Roberts 1987 & $?$ & + & + & + & $?$ & + & + & + \\
\hline Savin 1990a & $?$ & $?$ & + & $?$ & $?$ & + & + & + \\
\hline Savin $1990 \mathrm{~b}$ & $?$ & $?$ & + & $?$ & $?$ & $\odot$ & + & + \\
\hline Smith 2001 & $?$ & $?$ & - & - & $\Theta$ & $\Theta$ & + & - \\
\hline Svejgaard 1998 & $?$ & $?$ & $?$ & $?$ & $?$ & $\odot$ & + & $?$ \\
\hline Voravutinon 1993 & $?$ & $?$ & $?$ & $?$ & $?$ & + & + & + \\
\hline Widyanto 1993 & $?$ & $?$ & + & $?$ & $?$ & $\odot$ & + & $\odot$ \\
\hline Yamanchi 2000 & $?$ & + & + & $?$ & $?$ & + & + & $?$ \\
\hline
\end{tabular}


Figure 2. 'Risk of bias' graph: review authors' judgements about each 'Risk of bias' item presented as percentages across all included studies

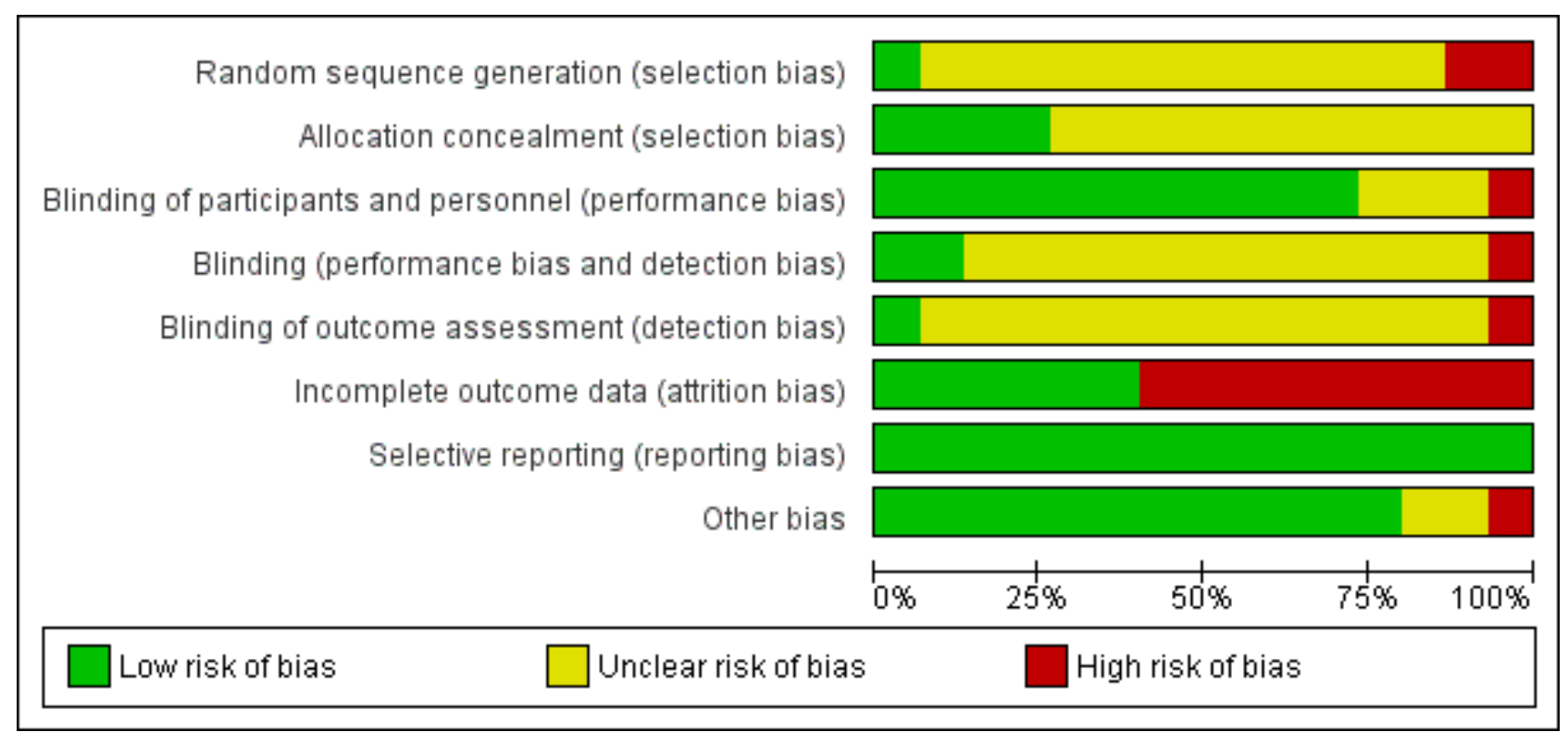

\section{Allocation}

\section{Adequacy of randomisation process}

All included trials were described as randomised, but only one reported the method used to generate the randomisation sequence: This was the DeKeyser 1994 study, which used a computer-generated randomisation list. We judged this to be at low risk of bias for this domain. We judged two trials to be at high risk of bias: Hay 1995 numbered each participant who was then given a treatment box; it was thought this may have been similar to an alternate model, and Hoharitanon 2005 did not report the method of generating the randomisation sequence. Also, there was a notable difference observed in the size of each trial arm with no explanation. We judged the remaining 12 trials as at unclear risk of bias.

\section{Allocation concealment}

We judged four trials to be at low risk of bias for this domain; DeKeyser 1994 used numbered boxes containing study medication; Hoharitanon 2005 used opaque sachets containing medication; Roberts 1987 used a third party, the hospital pharmacy, to provide medication; and Yamanchi 2000 used a randomisation code to conceal allocation. The remaining 11 trials did not report the allocation procedure, and we judged them to be at unclear risk of bias.

\section{Blinding}

\section{Participants and personnel}

Eleven trials achieved participant blinding through the use of tablets or capsules of similar appearance. Although some of these trials did not explicitly state that the participants were blinded, they did report double-blinding, and then went on to describe the identical appearance of the medication. It was then judged to be a reasonable assumption that the participants were therefore likely blinded (DeKeyser 1994; Difonzo 1995; Fischbein 1992; Hay 1995; Hoharitanon 2005; Kim 1993; Roberts 1987; Savin 1990a; Savin 1990b; Widyanto 1993; Yamanchi 2000). Three trials were unclear in their reporting (Nozickova 1998; Svejgaard 1998; Voravutinon 1993), and one study (Smith 2001) was reported as 'open label' and judged to be at high risk of bias.

\section{Treatment provider}

Two trials clearly achieved blinding of the treatment provider: Roberts 1987 used an independent third party to give the treatment, and DeKeyser 1994 used identical treatment boxes independently prepared. The remaining 12 trials did not report on the blinding of the treatment provider. Although the trials were, in some cases, reported as double-blind, it was not explicit who was blinded. Therefore, we judged this domain to be at unclear risk of bias. One study was open-label; therefore, it was not blinded and thus at high risk of bias (Smith 2001).

\section{Outcome assessor}

We judged one study to be at low risk of bias because it was reported that the outcome assessment was based on mycological testing alone and was carried out by a laboratory remote from the trial site (DeKeyser 1994). Thirteen trials did not explicitly report on the blinding of the outcome assessor. Therefore, they were judged to be at unclear risk of bias. One study was an open-label study (Smith 2001) and judged to be at high risk of bias.

\section{Incomplete outcome data}

We judged six trials to be at low risk of bias; two trials reported no attrition (Roberts 1987; Yamanchi 2000); and four trials had either low rates of attrition $(<5 \%)$ or reported the number lost to follow up with reasons: This number was within reasonable limits (Difonzo 1995; Hoharitanon 2005; Savin 1990a; Voravutinon 1993). However, the remaining nine trials were judged to be at high risk of bias as they had either high rates of attrition (>20\%) or made no attempts to justify exclusion of data or to account for the losses. The highest rate of attrition was substantial and was reported by DeKeyser 1994 (68\%). 


\section{Selective reporting}

There was no evidence of selective reporting, and trials were judged to be at low risk of bias for this domain. It is noteworthy that study protocols were not sought.

\section{Other potential sources of bias}

One study had an imbalance in the baseline duration of fungal infection, with the group treated with terbinafine $250 \mathrm{mg} /$ day for 2 weeks having a shorter duration of infection ( $151+/-163$ weeks) compared with the group treated with terbinafine $250 \mathrm{mg} /$ day for 4 weeks (376+/- 468 weeks) (Smith 2001). We judged two trials to be at unclear risk of bias for this domain (Svejgaard 1998; Yamanchi 2000). The remaining trials appeared to be free from other potential sources of bias.

The inclusion of tinea pedis caused by different fungal species (which was rarely reported on in the trials) was another potential source of bias in this field.

\section{Effects of interventions}

\section{Primary outcome - mycological cure}

\section{Antifungal compared with placebo}

Two trials compared antifungal treatments with placebo: 1 trial of terbinafine $(250 \mathrm{mg} /$ day for 6 weeks) and 1 trial of itraconazole (400 $\mathrm{mg} /$ day for 1 week) with placebo both found that the antifungal treatment was statistically significantly better than placebo (Savin 1990a; Svejgaard 1998). Both trials also demonstrated that the cure rate continued to improve beyond the end of treatment. In the case of terbinafine, $65 \%$ of participants were cured 2 weeks after the end of the 6-week treatment period (RR $24.54,95 \% \mathrm{Cl} 1.57$ to 384.32 ; Analysis 1.1). For itraconazole, $55 \%$ of participants were cured 8 weeks after the 1-week treatment period (RR $6.67,95 \% \mathrm{Cl} 2.17$ to 20.48; Analysis 1.2).

\section{Different types of antifungals}

\section{Allylamines versus azoles}

Four trials compared terbinafine ( $250 \mathrm{mg} /$ day for 2 weeks) and itraconazole $(100 \mathrm{mg} /$ day for either 2 weeks or 4 weeks) headto-head (DeKeyser 1994; Hay 1995; Kim 1993; Voravutinon 1993). Although 3 trials showed a higher cure rate for terbinafine, only 1 trial (DeKeyser 1994), which used itraconazole for 2 weeks, demonstrated a statistically significant difference in favour of terbinafine (RR $1.58,95 \% \mathrm{Cl} 1.24$ to 2.02; Analysis 2.1); terbinafine achieved a cure of $86 \%$ compared to itraconazole at $54 \%$.

Performing a meta-analysis (pooling of data from trials) achieves a more precise estimate of the treatment effect; however, the issue of heterogeneity is important. In considering clinical heterogeneity, the trials should look at a similar pool of participants, the same clinical condition, and have similar treatment periods and length of follow up. These issues are initially assessed visually by the researcher and then tested for statistical significance. As there was no evidence of heterogeneity $\left(I^{2}\right.$ statistic $\left.=0 \%\right)$ between the 3 trials with a common treatment length of 4 weeks, data for the final outcome measurements were pooled, using a fixed-effect model. This gave a risk ratio of 1.07 (95\% $\mathrm{Cl} 0.92$ to 1.25 ; Analysis 2.1), which was not statistically significant.

\section{Azole versus azole}

Fluconazole (50 mg/day) was compared with $100 \mathrm{mg} /$ day itraconazole (Difonzo 1995) and $200 \mathrm{mg} /$ day ketoconazole (Fischbein 1992). Both trials demonstrated broadly similar cure rates of about $90 \%$ for all 3 drugs. There was no statistically significant difference between fluconazole and itraconazole (RR $1.06,95 \% \mathrm{Cl} 0.87$ to 1.30 ; Analysis 2.2 ) nor was there any statistically significant difference between fluconazole and ketoconazole (RR $1.04,95 \% \mathrm{Cl} 0.92$ to 1.17 ; Analysis 2.3). However, as there were less than 30 evaluable participants in each intervention arm, the trials were not sufficiently powered to detect a significant difference. In addition, the trial data were poorly reported by Fischbein 1992. It was not clear if the unit of analysis was the individual participant or the infection site, and attempts to contact the trial authors to obtain clarification were unsuccessful.

One study (Hoharitanon 2005) compared 3 different brands of itraconazole ( $200 \mathrm{mg} /$ day for 2 weeks); 2 were generic brands and 1 was a new branded product. The study reported that there were cost implications, with the generic brands being cheaper. There were 133 evaluable participants, who were not allocated equally among the 3 arms. The trial reported that no statistically significant difference was detected between any of the groups (group 1: 11/18, group 2: 35/61, group 3: 27/54); these data were not plotted in a forest plot. It is worth noting that a cost analysis was not reported.

\section{Griseofulvin versus newer drugs}

One small trial compared griseofulvin (1000 mg/day) with ketoconazole ( $200 \mathrm{mg} /$ day), both for 4 weeks of treatment, and no difference in cure rates was seen (Roberts 1987) (Analysis 2.4). The trial had a total of 29 participants, which raises the question of a type Il error (not detecting a significant difference when there really is a difference of magnitude).

Two small trials compared griseofulvin $(500 \mathrm{mg} /$ day $)$ with terbinafine $(250 \mathrm{mg} /$ day) for either 4 (Widyanto 1993) or 6 weeks (Savin 1990b). Both trials showed that terbinafine had statistically significantly better cure rates, $100 \%$ and $86 \%$, whereas griseofulvin achieved $50 \%$ and $33 \%$. When the two trials were pooled, using a fixed-effect model $\left(I^{2}\right.$ statistic $\left.=0 \%\right)$, there was a statistically significant difference in favour of terbinafine (RR 2.26, $95 \% \mathrm{Cl} 1.49$ to 3.44; Analysis 2.5).

\section{Different doses or length of treatment}

There has been only 1 trial comparing different doses, and it compared fluconazole $50 \mathrm{mg}$ per day for a maximum of 6 weeks with fluconazole $150 \mathrm{mg}$ once a week for a maximum of 6 weeks (Nozickova 1998). No statistically significant difference in cure rates was achieved (Analysis 2.6), but the trial was small (total $n=51$ ).

One study compared terbinafine $250 \mathrm{mg}$ over 2 different treatment periods of 2 or 4 weeks in an open-label study. The study was small with 17 evaluable participants, all of whom were HIV positive. No significant difference was detected between the groups, with $50 \%$ $(5 / 10)$ achieving a cure when treated with terbinafine for 2 weeks and $43 \%(3 / 7)$ achieving a cure when treated for 4 weeks (RR 1.17, $95 \% \mathrm{Cl} 0.41$ to 3.36; Analysis 2.7) (Smith 2001).

\section{Bovine lactoferrin}

There has been 1 trial investigating bovine lactoferrin (LF) $600 \mathrm{mg}$ and $2000 \mathrm{mg}$ with placebo (Yamanchi 2000). There were a total 
of 37 participants with mild to moderate tinea pedis included in the study. No significance difference was reported between any of the groups. Results were presented in terms of 'dermatological improvement' scores, with the proportion of cases showing marked improvement or improvement: $42.9 \%(6 / 14)$ in the group treated with $600 \mathrm{mg} \mathrm{LF}, 41.7 \%$ (5/12) in the group treated with $2000 \mathrm{mg} \mathrm{LF}$, and $18.2 \%(2 / 11)$ in the placebo group. No mycological cure was achieved, and no adverse events were reported.

\section{Type of tinea pedis}

\section{Terbinafine versus itraconazole}

Another source of heterogeneity considered was the type of tinea pedis. We used a random-effects model to pool the data for the two trials that studied only plantar tinea pedis (Hay 1995; Kim 1993) and for the two trials that did not differentiate between interdigital and plantar tinea pedis (DeKeyser 1994; Voravutinon 1993). No statistically significant difference was shown (Analysis 3.1; Analysis 3.2).

\section{Summary of results for mycological cure rates}

- Terbinafine and itraconazole were more effective than no treatment (placebo).

- Terbinafine (two-weeks treatment) was more effective than itraconazole (two-weeks treatment).

- Terbinafine was more effective than griseofulvin.

- No significant difference in effectiveness was found between the following:

- two weeks of terbinafine versus four weeks of itraconazole;

- fluconazole versus either itraconazole or ketoconazole;

- griseofulvin and ketoconazole;

- different doses of fluconazole;

- different doses of terbinafine;

- different doses of bovine lactoferrin and placebo; or

- different brands of itraconazole but of the same dose.

The type of tinea pedis does not appear to influence response to oral antifungal treatment, but this is based on sparse data.

\section{Secondary outcomes}

All trials reported secondary outcomes, but differed in the format of presentation and detail.

\section{Clinical assessment}

We reported our secondary outcomes as an assessment of clinical signs and symptoms of the condition; these were exudation, erythema, scaling, vesiculation, pustules, crusting, desquamation, maceration, fissuring and pruritus, burning, rash, cellulitis, and pain. The trials assessed on average six different clinical signs and symptoms; most commonly, these were erythema, desquamation/ scaling, vesiculation, pustules, pruritus/itching, and maceration.

This assessment was usually a subjective scoring system where the individual sign or symptom was rated as absent, mild, moderate, or severe, and given a score from 0 to 3 . None of the trials reported that the outcome assessor was blind to treatment allocation.

The trials presented the results in several different ways making it more difficult to make direct comparisons but allowing trends to be identified. Most trials calculated the mean clinical score across all assessed signs and symptoms at a stated point in time. In contrast, some trials presented results as a percentage of the population whose score was two or less for a total of all signs and symptoms. In general, the average clinical scores tended to reduce as the cure rate increased.

\section{Measurement of recurrence}

Further outcome measures were considered, namely the incidence of recurrence of the condition and maintenance of a cured condition 12 weeks after the start of treatment. Only 3 trials (Hay 1995; Roberts 1987; Savin 1990b) assessed the condition at 12 weeks or beyond. Roberts 1987 compared ketoconazole and griseofulvin and did not report the cure rate at 12 weeks, but found that the mean clinical score for signs and symptoms continued to improve in both groups. However, Hay 1995 demonstrated a continued improvement for participants treated with terbinafine at week 16, but in the itraconazole group, the infection had begun to reappear. Savin 1990b showed $6 \%$ recurrence with terbinafine and $25 \%$ recurrence with griseofulvin, but this was demonstrated in a study with very small sample sizes.

\section{Cosmetic acceptability}

No trialists reported the cosmetic acceptability of the end result or the amount of discomfort. Svejgaard 1998 included pain as a clinical symptom, and Difonzo 1995 mentioned subjective symptoms, but no detail was reported.

\section{Adverse events}

These were recorded in all but one trial (Roberts 1987). In general, all treatment regimens resulted in some adverse events. It was also noted that where trials had a placebo arm, these participants also reported adverse events. In all trials, the most frequently reported events were associated with the gastrointestinal system, such as diarrhoea and nausea, followed by headaches and the occurrence of skin complaints, such as rash, dermatitis, and pruritus. Less frequently reported adverse events were those associated with dizziness, taste disorders, and respiratory infections. Nobody suffered side-effects that led to any long-term or lasting damage. None of the participants who were treated with bovine lactoferrin reported adverse effects; however, haematological tests were significantly different to baseline in the group treated with $2000 \mathrm{mg}$. Please see Analysis 4.1 for a summary of adverse events reported for trials of tinea pedis.

\section{Identified fungi}

The analysis of identified dermatophytes showed Trichophyton rubrum to be the most prevalent infecting organism in the participants evaluated in 13 out of the 15 trials included in this review.Trichophyton interdigitale (mentagrophytes) and Epidermophyton floccosum were also detected in these trials. Two trials included in this review reported Trichophyton mentagrophytes to be the most prevalent (Hoharitanon 2005; Widyanto 1993), and two trials (Smith 2001; Svejgaard 1998) did not report on infecting dermatophyte species. Although most trials identified the infecting species at baseline, none analysed the residual dermatophytes in individuals not cured.

\section{DISCUSSION}

Tinea pedis is a common disease of the skin, and in the majority of cases, it is caused by a dermatophyte infection. A number of factors 
may have contributed to the growing incidence of this infection, including an aging population and increasing participation in fitness and leisure-related activities.

In the UK, the National Health Service (NHS), the primary care team, and the affected individual make treatment decisions. One of the key decisions is the type of treatment, because antifungal drugs are available in either topical or oral form. Most topical treatments for tinea pedis are available over-the-counter and as such, are accessible for self-treatment, as well as being recommended by podiatrists and other healthcare professionals. Oral treatments are only available by prescription, and they are obtained through consultation with general practitioners, dermatologists, or nurse prescribers. Many of the advantages of oral treatment regimens are obvious; they are less time consuming and thought to have better compliance. It is recognised that oral treatments are best suited in the case of either topical treatment failures or more chronic presentations of tinea pedis.

This systematic review addressed the main research question regarding whether or not there is an effective oral treatment for tinea pedis and, if so, which treatment is most effective. Further research questions were as follows:

- Is there an optimum treatment duration?

- Is there an optimum dosage?

- Which intervention has fewest side-effects?

- Does any one clinical type of tinea pedis respond better to a particular treatment?

We have tried to answer these questions in our summary of the results below.

\section{Summary of main results}

We included 15 RCTs in the review. Of the included trials, only 5 were published in recent years, with the other 10 trials having been published pre-1996. This is an indication that research into establishing the most effective oral treatment for tinea pedis does not attract a high level of current interest; another explanation may be publication bias.

We considered trials that compared antifungal drugs with a placebo first as it is important to establish in the first instance whether a drug is actually effective when treating the target disease. There is evidence that both terbinafine and itraconazole are statistically significantly better than placebo.

- Is there an optimum dosage?

The evidence from 1 small trial showed that terbinafine $(250 \mathrm{mg})$ was statistically significantly better than itraconazole $(100 \mathrm{mg})$ when given for 2 weeks. However, this trial result was based on a final evaluable sample of one third of the original number recruited to the trial. The trialists did not report the reasons for the loss to follow up. A pooled comparison of trials comparing terbinafine with four weeks of itraconazole showed no difference between the two treatments that reached significance. Two small trials comparing terbinafine $(250 \mathrm{mg})$ with griseofulvin $(500 \mathrm{mg})$ demonstrated significant evidence that terbinafine cures $52 \%$ more participants than griseofulvin.
No difference was detected between ketoconazole and griseofulvin or between fluconazole and either ketoconazole or itraconazole. As only 106 participants took part in these 3 trials, however, there is a real danger of false negative findings. Similarly, the only dose-finding trial showed no significant difference between giving fluconazole for $50 \mathrm{mg}$ a day or $150 \mathrm{mg}$ a week.

- Does any one clinical type of tinea pedis respond better to a particular treatment?

The two most common types of tinea pedis are plantar (side of the foot) and interdigital (between the toes). The type of tinea pedis was described in all trials except four, but no significant difference was demonstrated in the effectiveness of any one drug with respect to location. Therefore, there is no clear data that the type of tinea pedis is an important factor for the clinician when deciding on oral drug treatment.

\section{- Is there an optimum treatment duration?}

With respect to length of treatment, terbinafine is routinely prescribed for 2 weeks ( $250 \mathrm{mg}$ daily), and the most commonly evaluated regimen for itraconazole was $100 \mathrm{mg}$ for 4 weeks. No trials investigated pulsing itraconazole, which gives $200 \mathrm{mg}$ of itraconazole twice daily for only 7 days and is a regimen that is being introduced into clinical practice (MIMS 2000). In all trials, terbinafine was given at the recommended dose of $250 \mathrm{mg}$ per day, but the treatment duration for terbinafine varied from 2 to 6 weeks in the trials, with the most frequent being 2 weeks. Terbinafine prescribed for 2 weeks at $250 \mathrm{mg}$ daily may be the optimum treatment period and dosage.

The effectiveness of oral antifungal drugs in treating secondary outcomes corresponded to their effectiveness in achieving primary outcomes. It appears that an antifungal drug's effectiveness in eradicating dermatophyte spores on the skin of the foot reflects the effectiveness of that drug in eradicating clinical signs and symptoms, such as scaling, pustules, itching, and burning.

\section{- Which intervention has fewest side-effects?}

Twelve of the 15 included trials reported side-effects, with gastrointestinal effects being the most frequently reported. The lack of reported information about the types of dermatophytes surviving the treatment regimens evaluated in participants with positive culture at last outcome prevented us from making any conclusions about the sensitivity of different species to each individual drug therapy.

The measurement of recurrence is important. There is little point in finding a drug treatment that achieves a good cure rate if the condition reappears some weeks after treatment has ended. The trials in this review were disappointing with respect to achieving good follow up, with only three trials assessing the condition beyond three months. Ideally, the condition should be reassessed 6 to 12 months after treatment has ended, and if findings demonstrate a continuation of the cured condition, this reinforces the effectiveness of the treatment. Whilst it is recognised that a long follow up adds to the cost of a trial, it is important that the most effective treatments be those that not only achieve good cure rates but reduce relapse of the condition. Long follow-up periods also increase the possibility of losing trial participants; five trials included in this review reported a decrease in the number 
of participants evaluable from those originally recruited to the trials. Concern must be expressed at any missing data that is not accounted for. Of course there is an ongoing discussion of whether it is relapse or re-infection that causes the infection to reappear. In the case of tinea pedis, it is a condition that can coexist with a nail infection, and unless both are treated together, the nail might well prove a source of reinfection for the skin. Whether it is recurrence of the original condition or a re-infection, preventative measures should be considered. Routine oral treatments for prophylactic use cannot be justified due to possible side-effects, drug interactions, and high costs; however, topical agents are a realistic alternative. Hart 1999 concluded that whilst allylamines (e.g. terbinafine) were slightly more effective than azoles (e.g. clotrimazole) for topical treatments of fungal skin and nail infections of the feet, the most cost-effective option was to treat initially with topical azoles and use topical allylamines for azole treatment failures. This would be a realistic treatment plan for tinea pedis.

In summary, terbinafine is more effective than griseofulvin, and one trial demonstrated evidence to support the use of terbinafine over itraconazole when given for a two-week treatment period.

No other treatment regimen was shown to be significantly more effective. The quality of reporting of the trials was variable, and in general, the method of generating the randomisation sequence and concealing allocation was not clearly reported, with the result that the trials were at unclear risk of bias for these domains. A similar omission was the lack of blinding of outcome assessors, especially with respect to the assessment of clinical signs and symptoms as this outcome is, by its nature, subjective.

\section{Potential biases in the review process}

\section{Conflict of interest and publication bias}

Because it was necessary to exclude those trials that reported combined data for the treatment of fungal infections of the skin of the hands and feet, the data set used in the analyses was incomplete. Whilst we did attempt to resolve this situation (e.g. to request separate data for feet), we had no productive responses from any of the authors of the excluded trials. The omission of this data may leave true effects of treatment undetected. Missing data is particularly relevant in drug trials in which a conflict of interest may arise in trials as a result of commercial sponsorship.

In this systematic review, six trials clearly received funding or support from pharmaceutical companies, the sponsoring companies being Novartis, formerly Sandoz Pharmaceuticals (terbinafine) (DeKeyser 1994; Hay 1995; Savin 1990a), and Janssen Pharmaceuticals, Inc. (itraconazole, ketoconazole) (Difonzo 1995; Roberts 1987; Svejgaard 1998). Four of these supported trials demonstrated a result in favour of the drug manufactured by the sponsor. Of the six trials not supported by a pharmaceutical company, only two showed significant differences between two treatment arms; the other four trials showed no difference.

Although drug companies did reply to our requests for information, no new trials were identified that had not already been located from the database searches.

\section{AUTHORS' CONCLUSIONS}

\section{Implications for practice}

Terbinafine and itraconazole are more effective than no treatment, and terbinafine appears to give a significantly better cure rate for tinea pedis than griseofulvin. In addition, terbinafine may require a shorter treatment period, which is preferable for maximising patient compliance.

\section{Implications for research}

In order to produce more reliable data, a rigorous evaluation of different drug therapies needs to be undertaken with larger sample sizes.

Little information was recorded in the trials about the effectiveness of specific oral antifungal drugs on specific dermatophytes. Future investigators should be advised to report the types of dermatophytes cultured at the last outcome assessment for the proportion of participants not cured. Collecting and reporting this information would not incur any additional costs to the research funding body as microscopy and culture at baseline and followup is the primary outcome measure in most trials. In addition, the clinical presentation of tinea pedis should be clearly diagnosed.

Future researchers should be encouraged to report baseline information about the study populations' lifestyles, hobbies, and activities, since it may be possible to detect differences in the types of infecting dermatophytes associated with different environments. An evaluation of epidemiological factors in tinea pedis was not possible from the data extracted from the trials, but ultimately, these may influence the effectiveness of antifungal treatments.

It is also important to continue to follow up and collect data for preferably six months after the end of the intervention period to inform whether or not the infection recurred.

\section{ACK N OWLEDGEMENTS}

For help with this review we thank the following people: Philip Young, Janette Colclough, Alison Eastwood, Trevor Sheldon, Jill Ferrari, Andrea Nelson, Hywel Williams, Tina Leonard, Ian Russell, Fay Crawford, Wendy Tyrrell, and the referees. In addition, we would like to thank the following people who were the external referees for the protocol: Rod Hay and Andrew Finlay (content experts), Sally Hollis (statistician), and Jack Tweed (consumer). Rachel Hart (RH) was a substantial contributor to the original version of this review, but she was not involved in the update.

The Cochrane Skin Group editorial base wishes to thank Urbà González who was the Key Editor for this updated review; Jo Leonardi-Bee and Philippa Middleton who were the Statistical and Methods Editors, respectively; the clinical referees, Rod Hay and Lisa Matricciani; and the consumer referee, Jack Tweed. 
R E F E R E N C E S

\section{References to studies included in this review}

DeKeyser 1994 \{published data only\}

De Keyser P, De Backer M, Massart DL, Westerlinck KJ. Two week oral treatment of tinea pedis, comparing terbinafine $(250 \mathrm{mg} /$ day) with itraconazole (100mg/day): a double blind multicentre study. British Journal of Dermatology 1994;130(Suppl 43):22-5.

\section{Difonzo 1995 \{published data only\}}

Difonzo EM, Papini M, Cilli P, Calandra P, Panconesi E. A double blind study comparison of itraconazole and fluconazole in tinea pedis and tinea manuum. Journal of the European Academy of Dermatology \& Venereology 1995;4(2):148-52.

\section{Fischbein 1992 \{published data only\}}

Fischbein A, Haneke E, Lacner K. Comparative evaluation of oral fluconazole and oral ketoconazole in the treatment of fungal infections of the skin. International Journal of Dermatology 1992;31(Suppl 2):12-6.

\section{Hay 1995 \{published data only\}}

Hay RJ, McGregor JM, Wuite J, Ryattk KS, Ziegler C, Clayton YM. A comparison of 2 weeks terbinafine $250 \mathrm{mg}$ /day with 4 weeks of itraconazole $100 \mathrm{mg} /$ day in plantar - type tinea pedis. British Journal of Dermatology 1995;132 132:604-8.

\section{Hoharitanon 2005 \{published data only\}}

Hoharitanon S, Chaichalotornkul J, Sindhupak W. A comparison of the efficacy between two Itraconazole generic products and the innovative Itraconazole in the treatment of tinea pedis. Journal of the Medical Association of Thailand 2005;88(Suppl 4):s167-72.

\section{Kim 1993 \{published data only\}}

Kim JH, Yoon KB. Single blind randomised study of terbinafine vs itraconazole in tinea pedis (two weeks vs four weeks). Terbinafine in the Treatment of Superficial Fungal Infections. Proceedings of the Asia-Pacific Symposium on Lamisil, Series: International Congress and Symposium 205. London: Royal Society of Medicine Services, 1993; Vol. 205:17-20.

\section{Nozickova 1998 \{published data only\}}

Nozickova M, Koudelkova V, Kulikova Z, Malina L, Urbanowski S, Silny W. A comparison of the efficacy of oral fluconazole, 150 $\mathrm{mg} /$ week versus $50 \mathrm{mg} /$ day, in the treatment of tinea corporis, tinea cruris, tinea pedis and cutaneous candidosis. International Journal of Dermatology 1998;37(9):703-5.

\section{Roberts 1987 \{published data only\}}

Roberts DT, Cox NH, Gentles JC, Babu KK. Comparison of ketoconazole and griseofulvin in the treatment of tinea pedis. Journal of Medical and Veterinary Mycology 1987;25(5):347-50.

\section{Savin 1990a \{published data only\}}

Savin R. Successful treatment of chronic tinea pedis (moccasin type) with terbinafine (Lamisil). Clinical Experimental Dermatology 1989;14(2):116-9.
Savin RC, Zaias N. Treatment of chronic moccasin type tinea pedis with terbinafine: a double-blind, placebo-controlled trial. Journal of American Academy of Dermatology 1990;23(4 Pt 2):804-7.

\section{Savin 1990b \{published data only\}}

Savin RC. Oral terbinafine versus griseofulvin in the treatment of moccasin-type tinea pedis. Journal of American Academy of Dermatology 1990;23(4 Pt 2):807-9.

Savin RC. Terbinafine (Lamisil) versus griseofulvin in moccasin type tinea pedis. Journal of Dermatological Treatment 1990;1(Suppl 2):43-6.

\section{Smith 2001 \{published data only\}}

Smith S, Houpt K, Rich P, LaMarca A, Weinberg JM, Alferez TS, et al. Short-duration oral Terbinafine for the treatment of tinea pedis in HIV-Positive patients. Cutis 2001;68(1 Suppl):30-9.

Svejgaard 1998 \{published data only\}

Svejgaard E, Avnstorp C, Wanscher B, Nilsson J, Heremans A. Efficacy and safety of short-term itraconazole in tinea pedis: a double-blind, randomized, placebo-controlled trial. Dermatology 1998;197(4):368-72.

\section{Voravutinon 1993 \{published data only\}}

* Voravutinon V. Double blind comparative study of the efficacy and tolerability of terbinafine with itraconazole in patients with tinea pedis. Terbinafine in the Treatment of Superficial Fungal Infections. Proceedings of the Asia-Pacific Symposium on Lamisil, Series: International Congress and Symposium 205. London: Royal Society of Medicine Services, 1993; Vol. 205:11-6.

\section{Widyanto 1993 \{published data only\}}

Widyanto, Budimulja U, Kuswadji, Kusmarinah B. A randomised double blind comparative study of terbinafine vs griseofulvin in tinea pedis. Terbinafine in the Treatment of Superficial Fungal Infections. Proceedings of the Asia-Pacific Symposium on Lamisil, Series: International Congress and Symposium 205. London: Royal Society of Medicine Services, 1993; Vol. 205:21-4.

\section{Yamanchi 2000 \{published data only\}}

Yamauchi K, Hiruma M, Yamazaki N, Wakabayashi H, Kuwata H, Teraguchi S, et al. Oral administration of bovine lactoferrin for treatment of tinea pedis. A placebo-controlled, double blind study. Mycoses 2000;43(5):197-202.

\section{References to studies excluded from this review}

Baldari 2000 \{published data only\}

Baldari U, Righini MG, Raccagni AA, Ghittoni L, Biggio P, Pau M, et al. Comparative double blind, double dummy study on the efficacy and safety of fluconazole $100 \mathrm{mg} /$ day versus terbinafine $250 \mathrm{mg} /$ day in the treatment of dermatomycoses. Giornale Italiano di Dermatologia e Venereologia 2000;135(2):229-235.

\section{Barnetson 1998 \{published data only\}}

Barnetson RS, Marley J, Bullen M, Brookman S, Cowen P, Ellis D, et al. Comparison of one week of oral terbinafine $(250 \mathrm{mg} /$ 
day) with four weeks of treatment with clotrimazole $1 \%$ cream in interdigital tinea pedis. British Journal of Dermatology 1998;139(4):675-8.

\section{Bortolussi 2007 \{published data only\}}

Bortolussi R, Moore DL, Robinson JL, Rousseau-Harsany E, Samson LM, MacDonald NE, et al. Antifungal agents for common paediatric infections [Les antifongiques dans le traitement des infections pediatriques courantes]. Paediatric \& Child Health 2007;12(10):875-883.

\section{Bortolussi 2008 \{published data only\}}

Bortolussi R, Moore DL, Robinson JL, Rousseau-Harsany E, Samson LM, MacDonald NE, et al. Antifungal agents for common paediatric infections. Canadian Journal of Infectious Diseases \& Medical Microbiology 2008;19(1):15-18.

\section{Brugmans 1969 \{published data only\}}

Brugmans J, Van Cutsem J. A three-stage clinical evaluation of etonam (R10 100) in the treatment of chronic athlete's foot. Dermatologica 1969;138(5):403-17.

\section{Decroix 2008 \{published data only\}}

Decroix J, Ausma J, Cauwenbergh G, Borgers M, Wouters L. The efficacy of oral treatment with pramiconazole in tinea pedis and tinea cruris/corporis: two exploratory phase lla trials. British Journal of Dermatology 2008;158(4):854-856.

\section{Degreef 1987 \{published data only\}}

Degreef H, Marian K, De Veyler H, Duprez K, Borghys A, Verhoeve L. Itraconazole in the treatment of dermatophytoses: a comparison of two daily dosages. Reviews of Infectious Diseases 1987;9(Suppl 1):S104-8.

\section{Del Palacio 1993 \{published data only\}}

Del Palacio A, Van Cutsem J, Lopez S, Roiz MP, Cuetaria MS, Iglesias $\mathrm{L}$, et al. Double blind randomised comparative study on tinea manuum and tinea pedis treated with itraconazole and griseofulvin [Estudio doble ciego aleatorio comparativo con itraconzol y griseofulvina en tinea manuum y tinea pedis]. Actas Dermo-Sifiliograficas 1993;84(1-2):45-53.

\section{Gupta 1999 \{published data only\}}

Gupta AK, Nolting S, de Prost Y, Delescluse J, Degreef H, Theissen $U$, et al. The use of itraconazole to treat cutaneous fungal infections in children. Dermatology 1999;199(3):248-252.

\section{Hay 1991 \{published data only\}}

Hay RJ, Logan RA, Moore MK, Midgely G, Clayton YM. A comparative study of terbinafine versus griseofulvin in 'dry type' dermatophyte infections. Journal of American Academy of Dermatology 1991;24(2 Pt 1):243-6.

\section{Humphreys 2004 \{published data only\}}

Humphreys F. Terbinafine. Journal of Drug Evaluation 2004;2(5):133-155

\section{Jolly 1983 \{published data only\}}

Jolly HW, Daily AD, Rex IH, Krupp I, Tromovitch TA, Stegman SJ, et al. A multicentre double-blind evaluation of ketoconazole in the treatment of dermatomycoses. Cutis 1983;31(2):208-10.

\section{Lachapelle 1992 \{published data only\}}

Lachapelle JM, De Doncker P, Tennstedt D, Cauwenbergh G, Janssen PA. Itraconazole compared with griseofulvin in the treatment of tinea corporis/cruris and tinea pedis/manus: an interpretation of the clinical results of all completed doubleblind studies with respect to the pharmacokinetic profile. Dermatology 1992;184(1):45-50.

Legendre 1980 \{published data only\}

Legendre R, Steltz M. A multi-center double blind comparison of ketoconazole and griseofulvin in the treatment of infections due to dermatophytes. Reviews of Infectious Diseases 1980;2(4):586-91.

\section{Lynfield 1974 \{published data only\}}

Lynfield YL, Littman ML, Feingold LE. Treatment of tinea pedis with micronized griseofulvin and tolnaftate. Cutis 1974;13(3):460-2

\section{Markova 2002 \{published data only\}}

Markova T. Clinical inquiries: What is the most effective treatment for tinea pedis (athlete's foot)?. Journal of Family Practice 2002;51(1):21.

\section{Russell 1960 \{published data only\}}

Russell B, Frain-Bell W, Stevenson CJ, Riddell RW, Djavahiszwili N, Morrison SL. Chronic ringworm infection of the skin and nails treated with griseofulvin. Report of a therapeutic trial. Lancet 1960;1(7135):1141-7.

\section{Schuller 1998 \{published data only\}}

Schuller J, Remme JJ, Rampen FH, Van Neer FC. Itraconazole in the treatment of tinea pedis and tinea manuum: comparison of two treatment schedules. Mycoses 1998;41(11-12):515-20.

Stengel 1995 \{published data only\}

Stengel F, Robles-Soto M, Galimberti R, Suchil P. Fluconazole versus ketoconazole in the treatment of dermatophytoses and cutaneous candidiasis. International Journal of Dermatology 1994;33(10):726-9.

\section{Tausch 1998 \{published data only\}}

Tausch I, Decroix J, Gwiezdzinski Z, Urbanowski S, Baran E, Ziarkiewicz M, et al. Short-term itraconazole versus terbinafine in the treatment of tinea pedis or manus. International Journal of Dermatology 1998;37(2):140-2.

Van Hecke 1988 \{published data only\}

Van Hecke E, Van Cutsem J. Double-blind comparison of itraconazole with griseofulvin in the treatment of tinea pedis and tinea manuum. Mycoses 1988;31(12):641-9.

\section{White 1991 \{published data only\}}

White JE, Perkins P, Evans EGV. Successful treatment of chronic tinea pedis and tinea manuum with Lamisil (terbinafine). British Journal of Dermatology 1990;123(Suppl 37):30.

White JE, Perkins PJ, Evans EG. Successful 2-week treatment with terbinafine (Lamisil) for moccasin tinea pedis and tinea manuum. British Journal of Dermatology 1991;125(3):260-2. 
Wishart 1994 \{published data only\}

Wishart JM. A double blind study of itraconazole vs griseofulvin in patients with tinea pedis and tinea manus. New Zealand Medical Journal 1994;107(975):126-8.

\section{Won 1993 \{published data only\}}

Won YH, Kim SJ, Lee HW, Chun IK. Clinical comparative study of terbinafine and itraconazole in the treatment of tinea pedis. Terbinafine in the Treatment of Superficial Fungal Infections. Proceedings of the Asia-Pacific Symposium on Lamisil, Series: International Congress and Symposium 205. London: Royal Society of Medicine Services, 1993; Vol. 205:7-10.

\section{Yao 1999 \{published data only\}}

Yao ZY, Liu YS, Wang C, Pan DH, Zheng ZC, Zhang XY, et al. Clinical observation on the efficacy of 1 week and 2 weeks treatment of itraconazole in tinea pedis. Chinese Journal of Dermatology 1999;32(5):360-1.

\section{References to studies awaiting assessment}

Decroix 1995 \{published data only\}

Decroix J. Tinea pedis (mocassin-type) treated with itraconazole. International Journal of Dermatology 1995;34(2):122-124.

\section{References to ongoing studies}

NCT00509275 \{ublished data only (unpublished sought but not used)\}

NCT00509275. A Study to Evaluate Efficacy and Safety of Three W0027 Regimens in the Treatment of Moccasin Type Tinea Pedis (MTTP). clinicaltrials.gov/ct2/show/NCT00509275.

\section{Additional references}

\section{Alderova 2008}

Alderova L, Baroskova A, Faldyna M. Lactoferrin: A review. Veterinari Medicina 2008;53(9):457-68.

\section{Auger 1993}

Auger P, Marquis G, Joly J, Attye A. Epidemiology of tinea pedis in marathon runners: prevalence of occult athlete's foot. Mycoses 1993;36(1-2):35-41.

\section{Begg 1989}

Begg CB, Berlin JA. Publication bias and dissemination of clinical research. Journal of the National Cancer Institute 1989;81(2):107-15.

\section{Brautigam 1995}

Brautigam M, Nolting S, Schopf G, Weidinger G. Randomised double blind comparison of terbinafine and itraconazole for the treatment of toenail tinea infection. Seventh Lamisil German Onychomycosis Study Group. BMJ 1995;311(7010):919-22.

\section{Brooks 1996}

Brooks KE, Bender JF. Tinea pedis diagnosis and treatment. Clinics in Podiatric Medicine \& Surgery 1996;13(1):31-46.

\section{Catterall 1975}

Catterall MD. The incidence and epidemiology of tinea pedis in the crew of a nuclear submarine. Journal of the Royal Naval Medical Service 1975;61(2):92-7.

\section{Detandt 1995}

Detandt M, Nolard N. Fungal contamination of the floors of swimming pools, particularly subtropical swimming paradises. Mycoses 1995;38(11-12):509-13.

\section{Elewski 1996}

Elewski BE. Diagnostic techniques for confirming onychomycosis. Journal of the American Academy of Dermatology 1996;35(3 Pt 2):S6-9.

\section{English 1959}

English MP, Gibson MD. Studies in the epidemiology of tinea pedis I. Tinea pedis in school children. BMJ 1959;1(5135):1442-6.

\section{English 1961}

English MP, Gibson MD, Warin RP. Studies in the epidemiology of tinea pedis: VI Tinea pedis in a boarding school. BMJ 1961;1:1083-5.

\section{Gentles 1957}

Gentles JC, Holmes JG. Foot ringworm in coal-miners. British Journal of Industrial Medicine 1957;14(1):22-9.

\section{Gentles 1973}

Gentles JC, Evans EG. Foot infections in swimming baths. BMJ 1973;3(5874):260-2.

\section{Gupta 1994a}

Gupta AK, Sauder DN, Shear NH. Antifungal agents: An overview. Part I. Journal of American Academy of Dermatology 1994;30(5 Pt 1):677-98.

\section{Gupta 1994b}

Gupta AK, Sauder MD, Shear NH. Antifungal agents: An overview. Part II. Journal of American Academy of Dermatology 1994;30(6):911-33.

\section{Hart 1999}

Hart R, Bell-Syer SE, Crawford F, Torgerson DJ, Young P, Russell I. Systematic review of topical treatment for fungal infections of the skin and nails of the feet. BMJ 1999;319(7202):79-82.

\section{Higgins 2003}

Higgins JP, Thompson SG, Deeks JJ, Altman DG. Measuring inconsistency in meta-analyses. BMJ 2003;327(7414):557-60.

\section{Higgins 2011}

Higgins JPT, Altman DG, Sterne JAC (editors). Chapter 8: Assessing risk of bias in included studies. In: Higgins JPT, Green S (editors). Cochrane Handbook for Systematic Reviews of Interventions. Version 5.1.0 [updated March 2011]. The Cochrane Collaboration 2011. Available from www.cochranehandbook.org. 


\section{Jones 1982}

Jones HE. Ketoconazole. Archives Dermatology 1982;118(4):217-9.

\section{Merlin 1999}

Merlin K, Kilkenny M, Plunkett A, Marks R. The prevalence of common skin conditions in Australian school students: 4 Tinea pedis. British J Dermatology 1999;140(5):897-901.

\section{MIMS 2000}

MIMS. Monthly Index of Medical Specialities. London: Haymarket Medical Ltd, 2000.

\section{Roseeuw 1999}

Roseeuw D. Achilles foot screening project: preliminary results of patients screened by dermatologists. Journal of the European Academy of Dermatology \& Venereology 1999;12(Suppl 1):S6-9.

\section{Wakabayashi 2000}

Wakabayashi H, Uchida K, Yamauchi K, Teraguchi S, Hayasawa $\mathrm{H}$, Yamaguchi $\mathrm{H}$. Lactoferrin given in food facilitates dermatophytosis cure in guinea pig models. Journal of Antimicrobial Chemotherapy 2000;46(4):595-602.

\section{References to other published versions of this review} Bell-Syer 2002

Bell-Syer SEM, Hart R, Crawford F, Torgerson DJ, TyrrellW, Russell I. Oral treatments for fungal infections of the skin of the foot.. Cochrane Database of Systematic Reviews 2002, Issue 2. [DOI: 10.1002/14651858.CD003584]

* Indicates the major publication for the study

\section{CHARACTERISTICS OF STUDIES}

Characteristics of included studies [ordered by study ID]

\section{DeKeyser 1994}

\begin{tabular}{|c|c|c|}
\hline Methods & \multicolumn{2}{|l|}{ This was a RCT. } \\
\hline Participants & $\begin{array}{l}\text { There were } 366 \text { partic } \\
\text { The total evaluable sa } \\
\text { Exclusion criteria of } \\
\text { - No systemic antifu } \\
\text { - No topical antifung }\end{array}$ & $\begin{array}{l}\text { ants in the original sample (tinea pedis). } \\
\text { nple was } 117 \text { participants (group } 1=51 \text { participants; group } 2=66 \text { ). } \\
\text { he trial } \\
\text { gals taken } 3 \text { months before the study } \\
\text { ls taken } 2 \text { weeks before the study }\end{array}$ \\
\hline Interventions & \multicolumn{2}{|c|}{$\begin{array}{l}\text { - Group 1: terbinafine } 250 \mathrm{mg} \text { - } 1 \text { active tablet and } 1 \text { placebo capsule taken orally daily for } 2 \text { weeks } \\
\text { - Group 2: itraconazole } 100 \mathrm{mg} \text { - } 1 \text { active capsule and } 1 \text { placebo tablet taken orally daily for } 2 \text { weeks }\end{array}$} \\
\hline Outcomes & \multicolumn{2}{|c|}{$\begin{array}{l}\text { Primary outcomes of the trial } \\
\text { 1. Cure, demonstrated by negative results on microscopy and no growth of dermatophyte in culture } \\
\text { Secondary outcomes of the trial } \\
\text { 1. Clinical signs and symptoms: exudation, erythema, scaling, vesiculation, pustules, crusting, pruritus } \\
\text { 2. Adverse events }\end{array}$} \\
\hline Notes & \multicolumn{2}{|c|}{$\begin{array}{l}\text { The study only accounted for } 11 \text { withdrawals. } \\
\text { Quote: 'Medical Department, Sandoz Pharmaceuticals, B-1030 Brussels, Belgium...' } \\
\text { Comment: Three of the study authors were employed by Sandoz Pharmaceuticals, which manufactur- } \\
\text { ers Terbinafine. There was no declaration about this in the trial report. }\end{array}$} \\
\hline \multicolumn{3}{|l|}{ Risk of bias } \\
\hline Bias & Authors' judgement & Support for judgement \\
\hline $\begin{array}{l}\text { Random sequence genera- } \\
\text { tion (selection bias) }\end{array}$ & Low risk & $\begin{array}{l}\text { Quote: "The randomisation was computer generated in balanced blocks of } \\
\text { four." }\end{array}$ \\
\hline
\end{tabular}


DeKeyser 1994 (Continued)

Allocation concealment Low risk Quote: "Eligible participants received a numbered box containing the study (selection bias)

\section{medication."}

Comment: Allocation was found to be adequately concealed by the numbered boxes.

\begin{tabular}{|c|c|c|}
\hline $\begin{array}{l}\text { Blinding of participants } \\
\text { and personnel (perfor- } \\
\text { mance bias) }\end{array}$ & Low risk & $\begin{array}{l}\text { Quote: "...a double-blind study." "...a double-dummy technique." "Each box } \\
\text { contained either terbinafine tablets } 250 \mathrm{mg} \text { and placebo capsules, or itracona- } \\
\text { zole capsules } 100 \mathrm{mg} \text { and placebo tablets." }\end{array}$ \\
\hline
\end{tabular}

All outcomes

Comment: Participants received a tablet and a capsule; the tablet was the active treatment and the capsule a placebo; the other group received a placebo table and an active capsule. The participants did not know which treatment they were receiving.

\begin{tabular}{|c|c|c|}
\hline $\begin{array}{l}\text { Blinding (performance } \\
\text { bias and detection bias) } \\
\text { All outcomes }\end{array}$ & Low risk & $\begin{array}{l}\text { Comment: It was not specifically reported that the treatment provider was } \\
\text { blinded; however, the numbered boxes all contained } 1 \text { tablet and } 1 \text { capsule. } \\
\text { Therefore, it would be assumed they were unaware of the type of medication } \\
\text { being given to participants. }\end{array}$ \\
\hline
\end{tabular}

Blinding of outcome as- Low risk Quote: "At each visit, concomitant medication was checked, clinical symptoms sessment (detection bias) rated and skin scrapings taken from the selected target lesion."

All outcomes

Comment: It was not clear if the outcome assessor rating the clinical symptoms was blind to treatment allocation, but the statistical analysis for the trial was based on mycological results. The mycological testing was undertaken in a central laboratory, and on balance, it is likely this domain is at low risk of bias.

\begin{tabular}{ll}
\hline $\begin{array}{l}\text { Incomplete outcome data } \\
\text { (attrition bias) }\end{array}$ & High risk \\
All outcomes & $\begin{array}{l}\text { Quote: "Sixty-six participants were enrolled in the study." "44 participants who } \\
\text { were eligible for evaluation..." }\end{array}$ \\
& $\begin{array}{l}\text { Comment: Those lost to follow up or excluded made up } 68 \% \text { of those initially } \\
\text { recruited. They were lost early in the treatment phase. }\end{array}$
\end{tabular}

\begin{tabular}{lll}
\hline $\begin{array}{l}\text { Selective reporting (re- } \\
\text { porting bias) }\end{array}$ & Low risk & $\begin{array}{l}\text { Comment: No study protocol was available. The outcomes stated in the meth- } \\
\text { ods of the trial were all reported in the results. The study was judged to be at } \\
\text { low risk of bias for this domain based on this assumption. }\end{array}$ \\
\hline Other bias & Low risk & Comment: This trial appeared to be free from other potential sources of bias. \\
\hline
\end{tabular}

Difonzo 1995

\begin{tabular}{ll}
\hline Methods & This was a RCT. \\
\hline Participants & The treatment setting was multicentre. \\
& There were 37 participants in the original sample. \\
& The total evaluable sample was 35 participants (group $1=17$ participants; group $2=18)$.
\end{tabular}

\section{Exclusion criteria of the trial}

- No systemic antifungals taken 1 month before the study

\begin{tabular}{ll}
\hline Interventions & Group 1: itraconazole $100 \mathrm{mg}$ - 1 capsule taken daily for 30 days \\
& - Group 2: fluconazole $50 \mathrm{mg}$ - 1 capsule taken orally daily for 30 days
\end{tabular}

\section{Outcomes}

\section{Primary outcomes of the trial}




\section{Secondary outcomes of the trial}

1. Clinical signs and symptoms: exudation, erythema, vesicles, desquamation, maceration, fissuring

2. Adverse events

Notes $\begin{aligned} & \text { One of the co-authors was affiliated to Janssen Farmaceutici, Italy; however, the source of funding was } \\ & \text { not declared. }\end{aligned}$
not declared.

\section{Risk of bias}

\begin{tabular}{lll}
\hline Bias & Authors' judgement & Support for judgement \\
\hline $\begin{array}{l}\text { Random sequence genera- } \\
\text { tion (selection bias) }\end{array}$ & Unclear risk & Comment: The method of randomisation was not reported. \\
\hline $\begin{array}{l}\text { Allocation concealment } \\
\text { (selection bias) }\end{array}$ & Unclear risk & Comment: It was not reported if allocation was concealed. \\
\hline $\begin{array}{l}\text { Blinding of participants } \\
\text { and personnel (perfor- } \\
\text { mance bias) }\end{array}$ & Low risk & $\begin{array}{l}\text { Quote: "...double-blind." "Itraconazole (100 mg) or fluconazole (50 mg, posolo- } \\
\text { gll outcomes } \\
\text { in a capsule formulation, once-daily with a meal for } 30 \text { days." }\end{array}$ \\
& $\begin{array}{l}\text { Comment: Participants received the same capsule regimen and number } \\
\text { of capsules. Whilst it was not specifically stated that the participants were } \\
\text { blinded, it was judged to be sufficient that the study was reported to be 'dou- } \\
\text { ble-blind'; therefore, this domain was judged to be low risk. }\end{array}$ \\
\hline
\end{tabular}

\begin{tabular}{|c|c|c|}
\hline $\begin{array}{l}\text { Blinding (performance } \\
\text { bias and detection bias) } \\
\text { All outcomes }\end{array}$ & Unclear risk & $\begin{array}{l}\text { Comment: There was no report regarding who allocated treatment or pro- } \\
\text { vided medication. It was not clear from the report whether the treatment } \\
\text { provider was blinded in this 'double-blind' study; therefore, this was judged to } \\
\text { be unclear risk. }\end{array}$ \\
\hline
\end{tabular}

\begin{tabular}{lll}
\hline Blinding of outcome as- & Unclear risk & $\begin{array}{l}\text { Quote: "Mycology testing, assessment of clinical and subjective symptoms of } \\
\text { sessment (detection bias) }\end{array}$ \\
All outcomes & $\begin{array}{l}\text { infection (erythema, desquamation, vesicles, exudation, maceration, fissuring) } \\
\text { and a physicians overall assessment... Symptoms were scored using a } 3 \text { point } \\
\text { scale." }\end{array}$
\end{tabular}

Comment: Participants were assessed in the same manner; however, it was unclear if blinding was ensured.

$\begin{array}{ll}\text { Incomplete outcome data Low risk } & \text { Quote: "Two of the } 37 \text { participants enrolled in the study were not included in } \\ \text { (attrition bias) } & \text { the efficacy analysis: one, treated with itraconazole, was lost to follow up and } \\ \text { All outcomes } & \text { the other treated with fluconazole, withdrew from the study due to elevated } \\ \text { SGOT and SGPT levels." }\end{array}$

Comment: The authors reported the number of participants lost to follow up. The attrition rate was $5 \%$.

\begin{tabular}{lll}
\hline $\begin{array}{l}\text { Selective reporting (re- } \\
\text { porting bias) }\end{array}$ & Low risk & $\begin{array}{l}\text { Comment: The study protocol was not available. However, the outcomes stat- } \\
\text { ed in the methods of the report were all described in the results and discus- } \\
\text { sion. }\end{array}$ \\
\hline Other bias & Low risk & Comment: This trial appeared to be free from other potential sources of bias. \\
\hline
\end{tabular}


Fischbein 1992

\begin{tabular}{|c|c|}
\hline Methods & This was a RCT. \\
\hline \multirow[t]{5}{*}{ Participants } & $\begin{array}{l}\text { The treatment setting was multicentre. } \\
\text { There were } 189 \text { participants in the original sample (fungal skin infection across multiple sites (tinea } \\
\text { pedis data were separated out)). }\end{array}$ \\
\hline & The total evaluable sample was 53 participants (group 1 = 27 participants; group 2 = 26). \\
\hline & Exclusion criteria of the trial \\
\hline & - No systemic or topical antifungals taken 3 days before the study \\
\hline & $\begin{array}{l}\text { It was unclear what the unit of analysis was; the trial authors did not respond to requests for clarifica- } \\
\text { tion. }\end{array}$ \\
\hline
\end{tabular}

\begin{tabular}{ll}
\hline Interventions & Group 1: fluconazole $50 \mathrm{mg}$ once daily for an average period of 4 weeks \\
& - Group 2: ketoconazole $200 \mathrm{mg}$ once daily for an average of 4 weeks
\end{tabular}

\section{Outcomes Primary outcomes of the trial}

1. Cure, demonstrated by negative results on microscopy and no growth of dermatophyte in culture

\section{Secondary outcomes of the trial}

1. Clinical signs and symptoms: exudation, erythema, vesicles, desquamation, maceration, fissuring

2. Adverse events: reported for multiple sites on the body

Notes The source of funding was not reported.

\section{Risk of bias}

\begin{tabular}{lll}
\hline Bias & Authors' judgement & Support for judgement \\
\hline $\begin{array}{l}\text { Random sequence genera- } \\
\text { tion (selection bias) }\end{array}$ & Unclear risk & Comment: The method of randomisation was not reported. \\
\hline $\begin{array}{l}\text { Allocation concealment } \\
\text { (selection bias) }\end{array}$ & Unclear risk & Comment: The authors did not report how allocation was concealed. \\
\hline $\begin{array}{l}\text { Blinding of participants } \\
\text { and personnel (perfor- } \\
\text { mance bias) }\end{array}$ & Low risk & $\begin{array}{l}\text { Quote: "...double-blind." "Fluconazole was supplied as 50-mg capsules and ke- } \\
\text { toconazole as identical appearing 200-mg capsules." }\end{array}$ \\
& $\begin{array}{l}\text { Comment: Participants received the same capsule regimen and number of } \\
\text { capsules. Whilst it was not specifically stated that participants were blinded, } \\
\text { the study was reported to be 'double-blind'. Therefore, we judged that the par- } \\
\text { ticipants were likely to be blinded and so at low risk of bias. }\end{array}$
\end{tabular}

Blinding (performance Unclear risk

bias and detection bias)

All outcomes

\begin{tabular}{ll}
\hline $\begin{array}{l}\text { Blinding of outcome as- } \\
\text { sessment (detection bias) } \\
\text { All outcomes }\end{array}$ & Unclear risk \\
\hline $\begin{array}{l}\text { Incomplete outcome data } \\
\text { (attrition bias) }\end{array}$ & High risk \\
All outcomes &
\end{tabular}

Comment: There was no report regarding who allocated treatment or provided medication. It is not clear from the report whether the treatment provider was blinded in this 'double-blind' study; therefore, we judged this to be at unclear risk. not reported if the outcome assessor was blinded. Therefore, we judged this to be at unclear risk. 
Fischbein 1992 (Continued)

were administered; and there was a lack of mycological and clinical data resulting in an overall potential for bias.

\begin{tabular}{lll}
\hline $\begin{array}{l}\text { Selective reporting (re- } \\
\text { porting bias) }\end{array}$ & Low risk & $\begin{array}{l}\text { Comment: The study protocol was not available. However, the outcomes stat- } \\
\text { ed in the methods of the report were all described in the results and discus- } \\
\text { sion. }\end{array}$ \\
\hline Other bias & $\begin{array}{l}\text { Quote: "The evaluable treatment groups were well matched in terms of base- } \\
\text { line demographic characteristics, duration of present infection and the mean } \\
\text { total signs and symptoms at baseline." }\end{array}$ \\
$\begin{array}{l}\text { Comment: The baseline demographics appeared to be equal. Multiple sites } \\
\text { were investigated. The trial appeared to be free from other sources of poten- } \\
\text { tial bias. }\end{array}$ &
\end{tabular}

Hay 1995

\begin{tabular}{ll}
\hline Methods & This was a RCT. \\
\hline Participants & There were 190 participants in the original sample (plantar type tinea pedis). \\
& The total evaluable sample was 129 participants (group $1=65$ participants; group $2=64$ ). \\
& Exclusion criteria of the trial \\
- No systemic antifungals taken 6 weeks before the study & No topical antifungals taken 7 days before the study \\
- No terbinafine or itraconazole taken for 3 months before the study
\end{tabular}

\section{Outcomes}

\section{Primary outcomes of the trial}

1. Cure, demonstrated by negative results on microscopy and no growth of dermatophyte in culture

\section{Secondary outcomes of the trial}

1. Clinical signs and symptoms: erythema, scaling, vesiculation, pruritus

2. Tolerability

3. Adverse events

Notes

Quote: "The authors would like to thank the staff from Sandoz UK, Sandoz Netherlands and Sandoz Austria for their help in running the study."

Comment: The authors declared help from Sandoz, a pharmaceutical company; however, they were not explicit in what help was given, e.g. financial.

\section{Risk of bias}

\begin{tabular}{lll}
\hline Bias & Authors' judgement & Support for judgement \\
\hline $\begin{array}{ll}\text { Random sequence genera- } \\
\text { tion (selection bias) }\end{array}$ & High risk & $\begin{array}{l}\text { Quote: "Participants meeting the entry criteria were screened } 1 \text { week prior } \\
\text { to entry into the study. Each participant was allocated a number and a corre- } \\
\text { sponding treatment pack containing two separate boxes." }\end{array}$
\end{tabular}



generated.

Allocation concealment $\quad$ Unclear risk Comment: It was not reported if allocation was concealed.
(selection bias)
(selection bias)

\begin{tabular}{ll}
\hline $\begin{array}{l}\text { Blinding of participants } \\
\text { and personnel (perfor- }\end{array}$ & Quote: "...double-blind." "...double-dummy." "Those participants randomised \\
mance bias) & to terbinafine received 12 active tablets for the first 14 days plus 14 place- \\
All outcomes & bo tablets for the second 14 days from box one and 28 placebo itraconazole \\
& tablets from the second box. Those participants randomised to itraconazole \\
& received 28 days of placebo terbinafine tablets in one box plus 28 active itra- \\
& conazole capsules in the second."
\end{tabular}

Comment: Participants received the same tablet regimen and number of tablets. Whilst it was not specifically stated that the participants were blinded, the study was reported 'double-blind'; therefore, we have judged that the participants were likely to be blinded and so at low risk of bias.

\begin{tabular}{|c|c|c|}
\hline $\begin{array}{l}\text { Blinding (performance } \\
\text { bias and detection bias) }\end{array}$ & Unclear risk & Quote: "...double-blind." \\
\hline All outcomes & & $\begin{array}{l}\text { Comment: There was no report regarding who allocated treatment or pro- } \\
\text { vided medication. It was not clear from the report whether the treatment } \\
\text { provider was blinded in this 'double-blind' study; therefore, we judged it to be } \\
\text { at unclear risk. }\end{array}$ \\
\hline
\end{tabular}

\begin{tabular}{|c|c|c|}
\hline $\begin{array}{l}\text { Blinding of outcome as- } \\
\text { sessment (detection bias) } \\
\text { All outcomes }\end{array}$ & Unclear risk & $\begin{array}{l}\text { Quote: "Skin scraping was taken and posted to a central laboratory at St } \\
\text { Thomas' Hospital for examination." "A clinical assessment was made at base- } \\
\text { line and each subsequent visit. The signs and symptoms of infection (erythe- } \\
\text { ma, scaling, vesiculation and pruritus) were rated using..." a scale. } \\
\text { Comment: Participants were assessed in the same manner; however, it was } \\
\text { unclear if blinding was ensured. All mycology results were carried out in a cen- } \\
\text { tral laboratory. }\end{array}$ \\
\hline
\end{tabular}

$\begin{array}{ll}\begin{array}{l}\text { Incomplete outcome data } \\ \text { (attrition bias) }\end{array} & \text { High risk } \\ \text { All outcomes } & \begin{array}{l}\text { Quote: "...190 participants, } 51 \text { were classified as delayed exclusions (all due to } \\ \text { negative culture at screening). Eight were classified as exclusions because they } \\ \text { did not return after the baseline (week 0) visit, two were protocol violations } \\ \text { (leaving } 129 \text { evaluable participants) } 65 \text { were randomised to terbinafine and } 64 \\ \text { to itraconazole." } \\ \text { Comment: All participants were accounted for. The attrition rate was } 32 \% .\end{array}\end{array}$

\begin{tabular}{lll}
\hline $\begin{array}{l}\text { Selective reporting (re- } \\
\text { porting bias) }\end{array}$ & Low risk & $\begin{array}{l}\text { Comment: The study protocol was not available. However, the outcomes stat- } \\
\text { ed in the methods of the report were all described in the results and discus- } \\
\text { sion. }\end{array}$ \\
\hline Other bias & Low risk & Quote: "Both groups were well matched for age and sex." \\
& $\begin{array}{l}\text { Comment: The baseline demographics were similar in both arms. We identi- } \\
\text { fied no other sources of potential bias. }\end{array}$
\end{tabular}

\section{Hoharitanon 2005}

\begin{tabular}{ll}
\hline Methods & This was a RCT. \\
\hline Participants & There were 140 participants in the initial sample.
\end{tabular}

Participants There were 140 participants in the initial sample. 
Hoharitanon 2005 (Continued)

The total evaluable sample was 133 participants, who were not distributed equally between groups (group 1 = 18 participants; group $2=61$ participants; group $3=54$ participants).

\section{Exclusion criteria of the trial}

- No topical therapy antifungal therapy within 30 days of the study

- No systemic antifungal therapy within 2 months of the study

- Chronic diseases, e.g. congestive heart failure

- Gastric and liver disorders

- Immunosuppression

- Women of childbearing age

- Pregnant and lactating women

- Participants with known hypersensitivity to itraconazole or taking drugs with known interactions

\begin{tabular}{ll}
\hline Interventions & Group 1: itraconazole (Sporal) $200 \mathrm{mg}$ twice daily for 1 week \\
- Group 2: itraconazole (Itracon) $200 \mathrm{mg}$ twice daily for 1 week \\
- Group 3: itraconazole (Itra) $200 \mathrm{mg}$ twice daily for 1 week
\end{tabular}

\section{Outcomes}

\section{Primary outcomes of the trial}

1. Cure, demonstrated by negative results on microscopy and culture

\section{Secondary outcomes of the trial}

1. Reduction in clinical signs and symptoms

2. Adverse Events

Notes

\section{Risk of bias}

\begin{tabular}{lll}
\hline Bias & Authors' judgement & Support for judgement \\
\hline $\begin{array}{l}\text { Random sequence genera- } \\
\text { tion (selection bias) }\end{array}$ & High risk & $\begin{array}{l}\text { Comment: The method of randomisation was not reported. Uneven groups } \\
\text { were generated. }\end{array}$ \\
\hline $\begin{array}{l}\text { Allocation concealment } \\
\text { (selection bias) }\end{array}$ & Low risk & $\begin{array}{l}\text { Quote: "Twenty-eight capsules of each were put into a non-transparent en- } \\
\text { closed sachet by randomised method." }\end{array}$ \\
& $\begin{array}{l}\text { Comment: Each trial arm had the same number of tablets in concealed opaque } \\
\text { sachets. Although the report did not state that these sachets were sequentially } \\
\text { numbered, we have taken the view that allocation concealment was achieved. }\end{array}$
\end{tabular}

$\begin{array}{ll}\begin{array}{l}\text { Blinding of participants } \\ \text { and personnel (perfor- }\end{array} & \text { Quote: "...double blind." } \\ \begin{array}{l}\text { mance bias) } \\ \text { All outcomes }\end{array} & \begin{array}{l}\text { Comment: All participants received the same tablet regimen and number of } \\ \text { tablets. Whilst it was not specifically stated if the participants were blinded, it } \\ \text { was felt they were likely to be unaware of which study group they had been al- } \\ \text { located; therefore, we judged this domain to be at low risk. }\end{array}\end{array}$

\begin{tabular}{|c|c|c|}
\hline $\begin{array}{l}\text { Blinding (performance } \\
\text { bias and detection bias) }\end{array}$ & Unclear risk & $\begin{array}{l}\text { Comment: There was no report regarding where the tablets were accessed } \\
\text { from/their distribution/how instructions were given. }\end{array}$ \\
\hline
\end{tabular}
All outcomes

\begin{tabular}{|c|c|c|}
\hline $\begin{array}{l}\text { Blinding of outcome as- } \\
\text { sessment (detection bias) }\end{array}$ & Unclear risk & $\begin{array}{l}\text { Comment: It was not clear from the report whether the outcome assessor was } \\
\text { blinded; therefore, we judged this to be at unclear risk. }\end{array}$ \\
\hline
\end{tabular}


Hoharitanon 2005 (Continued)

Incomplete outcome data Low risk Quote: "The study initially included 140 participants, 133 of them completed (attrition bias)

all the phases of they study and met all the criteria."

All outcomes

Comment: The authors did not specifically describe why 7 participants were not included in analysis. The attrition rate was $5 \%$.

Selective reporting (re- Low risk porting bias)

Comment: The study protocol was not available. However, the outcomes stated in the methods of the report were all described in the results and discussion.

Other bias Low risk Comment: This appeared to be free from other potential sources of bias.

\section{Kim 1993}

\begin{tabular}{ll}
\hline Methods & This was a RCT. \\
\hline Participants & There were 66 participants in the original sample (moccasin type tinea pedis). \\
& The total evaluable sample was 44 participants (group $1=22$ participants; group 2 = 22). \\
& Exclusion criteria of the trial \\
- Concomitant antifungal therapy was not allowed & Group 1: terbinafine 250 mg taken orally once daily for 2 weeks followed by placebo taken orally once \\
& daily for 2 weeks \\
\hline Interventions & Group 2: itraconazole 100 mg tablet taken orally once daily for 4 weeks
\end{tabular}

\section{Outcomes}

\section{Primary outcomes of the trial}

1. Cure, demonstrated by negative results on microscopy and no growth of dermatophyte in culture

\section{Secondary outcomes of the trial}

1. Clinical signs and symptoms: exudation, erythema, scaling, vesiculation, pustules, crusting, pruritus

2. Adverse events

\begin{tabular}{|c|c|c|}
\hline Notes & - & \\
\hline \multicolumn{3}{|l|}{ Risk of bias } \\
\hline Bias & Authors' judgement & Support for judgement \\
\hline $\begin{array}{l}\text { Random sequence genera- } \\
\text { tion (selection bias) }\end{array}$ & Unclear risk & $\begin{array}{l}\text { Quote: "...single blind randomised study." } \\
\text { Comment: The method of randomisation was not reported. }\end{array}$ \\
\hline $\begin{array}{l}\text { Allocation concealment } \\
\text { (selection bias) }\end{array}$ & Unclear risk & $\begin{array}{l}\text { Comment: There was no report on whether or not allocation concealment was } \\
\text { achieved. }\end{array}$ \\
\hline $\begin{array}{l}\text { Blinding of participants } \\
\text { and personnel (perfor- } \\
\text { mance bias) } \\
\text { All outcomes }\end{array}$ & Low risk & $\begin{array}{l}\text { Quote: "...single blind study." "Participants were randomised to receive either } \\
\text { terbinafine } 250 \mathrm{mg} \text { once daily for two weeks followed by placebo for two weeks } \\
\text { or itraconazole } 100 \mathrm{mg} \text { once daily for four weeks." } \\
\text { Comment: This study was described as single-blind, and it appeared that ef- } \\
\text { forts were made to ensure the medication regimen was the same for both } \\
\text { groups. Therefore, this domain was judged to be low risk. }\end{array}$ \\
\hline
\end{tabular}


Kim 1993 (Continued)

Blinding (performance bias and detection bias) All outcomes

Unclear risk

Comment: It was not clear from the report whether the treatment provider was blinded in this "single blinded" study; therefore, this was judged to be at unclear risk.

\begin{tabular}{lll}
$\begin{array}{l}\text { Blinding of outcome as- } \\
\text { sessment (detection bias) } \\
\text { All outcomes }\end{array}$ & Unclear risk & $\begin{array}{l}\text { Comment: It was not clear from the report whether the outcome assessor was } \\
\text { blinded in this "single blinded" study; therefore, this was judged to be at un- } \\
\text { clear risk. }\end{array}$ \\
\hline $\begin{array}{l}\text { Incomplete outcome data } \\
\text { (attrition bias) }\end{array}$ & High risk & $\begin{array}{l}\text { Quote: "Sixty-six participants were enrolled in the study." "...44 participants } \\
\text { who were eligible for evaluation." }\end{array}$ \\
& $\begin{array}{l}\text { Comment: Those lost to follow up or excluded made } 33 \% \text { of those initially re- } \\
\text { cruited. They were lost early in the treatment phase. }\end{array}$
\end{tabular}

\begin{tabular}{lll}
\hline $\begin{array}{l}\text { Selective reporting (re- } \\
\text { porting bias) }\end{array}$ & Low risk & $\begin{array}{l}\text { Comment: The study protocol was not available. However, the outcomes stat- } \\
\text { ed in the methods of the report were all described in the results and discus- } \\
\text { sion. }\end{array}$ \\
\hline Other bias & Low risk & Comment: This appeared to be free from other sources of potential bias. \\
\hline
\end{tabular}

Nozickova 1998

\begin{tabular}{ll}
\hline Methods & This was a RCT. \\
\hline Participants & The treatment setting was a hospital. \\
& There were 114 participants in the initial sample (tinea pedis, tinea cruris, tinea corporis). \\
& The total evaluable sample was 63 participants (group $1=34$ participants; group $2=29$ participants). \\
& Exclusion criteria of the trial \\
- Not stated & - Group 1: fluconazole 150 mg once weekly for a maximum of 6 weeks \\
\hline Interventions & Group 2: fluconazole 50 mg once daily for a maximum of 6 weeks \\
& The intervention ceased when a cured condition was achieved.
\end{tabular}

\section{Outcomes Primary outcomes of the trial}

1. Cure, demonstrated by negative results on microscopy and no growth of dermatophyte in culture

\section{Secondary outcomes of the trial}

1. Clinical efficiency based on a cured condition and an assessment of clinical signs and symptoms

2. Adverse events (number of events)

\section{Notes}

\section{Risk of bias}

\begin{tabular}{lll}
\hline Bias & Authors' judgement & Support for judgement \\
\hline $\begin{array}{l}\text { Random sequence genera- } \\
\text { tion (selection bias) }\end{array}$ & Unclear risk & Comment: The method of randomisation was not reported. \\
\hline $\begin{array}{l}\text { Allocation concealment } \\
\text { (selection bias) }\end{array}$ & Unclear risk & Comment: The authors did not report how allocation was concealed. \\
\hline \hline
\end{tabular}


Nozickova 1998 (Continued)

Blinding of participants Unclear risk Comment: Participants received different regimens; 1 group received daily and personnel (perfortreatment, and the other received weekly treatment. It was not specifically remance bias)

All outcomes ported if the participants were blinded or if placebo tablets were given; therefore, this domain was judged to be at unclear risk.

\begin{tabular}{|c|c|c|}
\hline $\begin{array}{l}\text { Blinding (performance } \\
\text { bias and detection bias) }\end{array}$ & Unclear risk & $\begin{array}{l}\text { Comment: There was no report regarding who allocated treatment or provid- } \\
\text { ed medication and if they were blinded. }\end{array}$ \\
\hline
\end{tabular}

All outcomes

Blinding of outcome as- Unclear risk sessment (detection bias) All outcomes
Comment: There was no report regarding who assessed outcome or if they were blinded.
Incomplete outcome data High risk

(attrition bias)

All outcomes
Quote: "Two hundred and forty five participants...22 were randomised to the once weekly regimen and 123 to the once daily regimen." "The number of un evaluable participants ( 42 in the once-weekly group and 57 in the once daily group)..."

Comment: The authors reported the number of participants who were not evaluable, but offered no reason why. The attrition rate was $36 \%$.

\begin{tabular}{lll}
\hline $\begin{array}{l}\text { Selective reporting (re- } \\
\text { porting bias) }\end{array}$ & Low risk & $\begin{array}{l}\text { Comment: The study protocol was not available. However, the outcomes stat- } \\
\text { ed in the methods of the report were all described in the results and discus- } \\
\text { sion. }\end{array}$ \\
\hline Other bias & Low risk & $\begin{array}{l}\text { Comment: Multiple sites were investigated. The trial appeared to be free from } \\
\text { other sources of potential bias. }\end{array}$ \\
\hline
\end{tabular}

\section{Roberts 1987}

\begin{tabular}{ll}
\hline Methods & This was a RCT. \\
\hline Participants & The treatment setting was a hospital. \\
& There were 29 participants in the initial sample (tinea pedis). \\
The total evaluable sample was 29 participants (group $1=15$ participants; group $2=14$ participants). \\
Exclusion criteria of the trial \\
- Not stated \\
\hline Interventions \\
- Group 1: ketoconazole 200 mg once daily for 4 weeks \\
In both groups, participants were offered further treatment of up to 4 weeks in duration if the primary \\
outcome of cure had not been achieved.
\end{tabular}

\section{Outcomes Primary outcomes of the trial}

1. Cure, demonstrated by negative results on microscopy and no growth of dermatophyte in culture

\section{Secondary outcomes of the trial}

1. Clinical signs and symptoms: peeling, maceration, fissuring, weeping, bleeding, itching, burning

2. Adverse events (these were not reported) 
Roberts 1987 (Continued)

Risk of bias

\begin{tabular}{lll}
\hline Bias & Authors' judgement & Support for judgement \\
\hline $\begin{array}{ll}\text { Random sequence genera- } \\
\text { tion (selection bias) }\end{array}$ & $\begin{array}{l}\text { Unclear risk } \\
\text { Quote: "Participants with mycologically proven tinea pedis were randomly al- } \\
\text { located to oral treatment with ketoconazole } 200 \mathrm{mg} \text { daily or griseofulvin } 1 \mathrm{~g} \\
\text { daily." }\end{array}$ & Comment: The method of randomisation was not reported. \\
\hline
\end{tabular}

$\begin{array}{ll}\begin{array}{l}\text { Allocation concealment } \\ \text { (selection bias) }\end{array} & \text { Low risk } \\ & \begin{array}{l}\text { Quote: "Both drugs were allocated to the participants by the hospital pharma- } \\ \text { cle daily dose with a meal." }\end{array} \\ & \begin{array}{l}\text { Comment: Both trial arms were managed in an identical manner with a third } \\ \text { party (pharmacy) providing medication; therefore, concealment was achieved. }\end{array}\end{array}$

\begin{tabular}{|c|c|c|}
\hline $\begin{array}{l}\text { Blinding of participants } \\
\text { and personnel (perfor- } \\
\text { mance bias) } \\
\text { All outcomes }\end{array}$ & Low risk & $\begin{array}{l}\text { Quote: "...double-blind". } \\
\text { Comment: All participants received medication that appeared the same and } \\
\text { followed the same instructions; it was judged to be blinded at this level. }\end{array}$ \\
\hline
\end{tabular}

\begin{tabular}{|c|c|c|}
\hline $\begin{array}{l}\text { Blinding (performance } \\
\text { bias and detection bias) }\end{array}$ & Low risk & Quote: "...double-blind". \\
\hline All outcomes & & $\begin{array}{l}\text { Comment: Medication was supplied by Janssen Pharmaceuticals Ltd and was } \\
\text { allocated to participants by the hospital pharmacy. It was felt that as iden- } \\
\text { tical packaging and instructions were given with medication, the treatment } \\
\text { provider was not aware which arm the participant belonged to. }\end{array}$ \\
\hline
\end{tabular}

\begin{tabular}{|c|c|c|}
\hline $\begin{array}{l}\text { Blinding of outcome as- } \\
\text { sessment (detection bias) }\end{array}$ & Unclear risk & $\begin{array}{l}\text { Quote: "Participants were observed by a single observer before commencing } \\
\text { treatment and at weeks 2, 4, } 8 \text { and } 12 . "\end{array}$ \\
\hline All outcomes & & $\begin{array}{l}\text { Comment: Though a single observer collected clinical data and skin scrapings, } \\
\text { it was not reported if this observer was blind. }\end{array}$ \\
\hline
\end{tabular}

Incomplete outcome data Low risk Comment: No participant data were lost.

(attrition bias)

All outcomes

\begin{tabular}{ll}
$\begin{array}{l}\text { Selective reporting (re- } \\
\begin{array}{l}\text { porting bias) } \\
\end{array}\end{array}$ & $\begin{array}{l}\text { Comment: The study protocol was not available. However, the outcomes stat- } \\
\text { ed in the methods of the report were all described in the results and discus- } \\
\text { sion. }\end{array}$ \\
\hline
\end{tabular}

Other bias Low risk Comment: The study appeared to be free from other sources of bias.

Savin 1990a

\begin{tabular}{ll}
\hline Methods & This was a RCT. \\
\hline Participants & The trial was conducted across 2 treatment centres. \\
& There were 50 participants in the initial sample (moccasin type tinea pedis). \\
The total evaluable sample was 41 participants (group $1=23$ participants; group $2=18$ participants). \\
Exclusion criteria of the trial \\
- Any radiotherapy, treatment with cytostatic or immunosuppressant drugs, antibiotics, antifungals, \\
antivirals or antiparasitics within 2 weeks prior to the study
\end{tabular}


Savin 1990a (Continued)

Interventions

- Group 1: terbinafine $125 \mathrm{mg}$ taken twice daily for 6 weeks

- Group 2: placebo taken twice daily for 6 weeks

\section{Outcomes}

\section{Primary outcomes of the trial}

1. Cure, demonstrated by negative results on microscopy and no growth of dermatophyte in culture

\section{Secondary outcomes of the trial}

1. Clinical signs and symptoms: erythema, scaling, vesiculation, pustules, pruritus

2. Adverse events: number of participants (number of events)

Notes This was funded in part by a pharmaceutical company - Sandoz Pharmaceuticals Corp.

\section{Risk of bias}

Bias Authors' judgement Support for judgement

Random sequence genera- Unclear risk tion (selection bias)

Quote: "Participants were randomly allocated to active or placebo group."

Comment: The method of randomisation was not reported.

Allocation concealment Unclear risk Comment: There was no mention of allocation concealment.
(selection bias)

\begin{tabular}{|c|c|c|}
\hline $\begin{array}{l}\text { Blinding of participants } \\
\text { and personnel (perfor- } \\
\text { mance bias) }\end{array}$ & Low risk & $\begin{array}{l}\text { Quote: "Participants were randomly allocated to active (oral terbinafine } \\
125 \mathrm{mg} \text { ) or placebo groups and were treated in double-blind fashion twice c } \\
\text { ly for a period of } 6 \text { weeks." }\end{array}$ \\
\hline All outcomes & & $\begin{array}{l}\text { Comment: Whilst it was not specifically stated how the participants were } \\
\text { blinded, it was judged to be sufficient that the study was reported "double } \\
\text { blind"; therefore, this domain was judged to be at low risk. }\end{array}$ \\
\hline
\end{tabular}

\begin{tabular}{|c|c|c|}
\hline $\begin{array}{l}\text { Blinding (performance } \\
\text { bias and detection bias) } \\
\text { All outcomes }\end{array}$ & Unclear risk & $\begin{array}{l}\text { Comment: It was not clear from the report whether the treatment provider was } \\
\text { blinded in this "double blinded" study. Therefore, it was judged to be at un- } \\
\text { clear risk. }\end{array}$ \\
\hline
\end{tabular}

\begin{tabular}{|c|c|c|}
\hline $\begin{array}{l}\text { Blinding of outcome as- } \\
\text { sessment (detection bias) } \\
\text { All outcomes }\end{array}$ & Unclear risk & $\begin{array}{l}\text { Comment: It was not clear from the report whether the outcome assessor was } \\
\text { blinded in this "double blinded" study; therefore, it was judged to be at un- } \\
\text { clear risk. }\end{array}$ \\
\hline
\end{tabular}

\begin{tabular}{ll}
\hline $\begin{array}{l}\text { Incomplete outcome data } \\
\text { (attrition bias) }\end{array}$ & Low risk \\
All outcomes & tures [and were] therefore excluded." "There were seven drop outs: four par- \\
& ticipants lost to follow up (two treated with terbinafine, two with placebo), one \\
& $\begin{array}{l}\text { participant due to elevated liver function tests (placebo) and another [due to] } \\
\text { concurrent treatment with antibiotics (placebo)." }\end{array}$
\end{tabular}

Comment: Exclusions were reported. The final analysis was undertaken in 41 of the participants who were initially recruited (50 participants), representing an attrition rate of $18 \%$.

\begin{tabular}{ll}
\hline $\begin{array}{l}\text { Selective reporting (re- } \\
\text { porting bias) }\end{array}$ & Low risk \\
& $\begin{array}{l}\text { Comment: The study protocol was not available. However, the outcomes stat- } \\
\text { ed in the methods of the report were all described in the results and discus- } \\
\text { sion. }\end{array}$
\end{tabular}

Other bias Low risk Comment: The study appeared to be free from other sources of bias.


Savin 1990b

\begin{tabular}{ll}
\hline Methods & This was a RCT. \\
\hline Participants & There were 36 participants in the initial sample (moccasin type tinea pedis). \\
& The total evaluable sample was 28 participants (group $1=16$ participants; group $2=12$ participants). \\
& Exclusion criteria of the trial \\
- No topical agents taken 2 weeks before the start of the study & No systemic agents 4 weeks before the start of the study \\
\hline Interventions & - Group 1: terbinafine $125 \mathrm{mg}$ taken twice daily for 6 weeks \\
& - Group 2: griseofulvin $250 \mathrm{mg}$ (microsize) taken twice daily for 6 weeks
\end{tabular}

\section{Outcomes}

\section{Primary outcomes of the trial}

1. Cure, demonstrated by negative results on microscopy and no growth of dermatophyte in culture

\section{Secondary outcomes of the trial}

1. Clinical signs and symptoms: erythema, pustules, pruritus, desquamation, hyperkeratosis

2. Adverse events

\section{Notes}

\section{Risk of bias}

\begin{tabular}{lll}
\hline Bias & Authors' judgement & Support for judgement \\
\hline $\begin{array}{l}\text { Random sequence genera- } \\
\text { tion (selection bias) }\end{array}$ & Unclear risk & Quote: "Prior to breaking randomisation code..." \\
& & $\begin{array}{l}\text { Comment: Limited details on randomisation were reported; however, the au- } \\
\text { thor stated that whilst making follow-up telephone calls, the randomisation } \\
\text { code was not broken, suggesting this was in place. However, this was not ex- } \\
\text { plicit; therefore, this domain was regarded as at unclear risk. }\end{array}$
\end{tabular}

Allocation concealment $\quad$ Unclear risk Comment: It was not reported if allocation concealment was achieved.
(selection bias)

\begin{tabular}{ll}
\hline $\begin{array}{l}\text { Blinding of participants } \\
\text { and personnel (perfor- } \\
\text { mance bias) }\end{array}$ & Low risk \\
All outcomes & $\begin{array}{l}\text { Quote: "Double randomised study.." "Terbinafine } 125 \mathrm{mg} \text { twice daily with grise- } \\
\text { ofulvin } 250 \mathrm{mg} \text { twice daily for } 6 \text { weeks..." }\end{array}$ \\
& $\begin{array}{l}\text { Comment: Both arms of participants received the same tablet regime and the } \\
\text { same number of tablets. Whilst it was not specifically stated how the partici- } \\
\text { pants were blinded, it was judged to be sufficient that the study was reported } \\
\text { 'double blind'; therefore, this domain was judged to be at low risk. }\end{array}$
\end{tabular}

\begin{tabular}{lll}
\hline $\begin{array}{l}\text { Blinding (performance } \\
\text { bias and detection bias) } \\
\text { All outcomes }\end{array}$ & Unclear risk & $\begin{array}{l}\text { Comment: There was no reporting on who allocated/provided medication and } \\
\text { how this was done. It was not clear from the report whether the treatment } \\
\text { provider was blinded in this 'double blinded' study; therefore, we judged this } \\
\text { to be at unclear risk. }\end{array}$ \\
\hline $\begin{array}{l}\text { Blinding of outcome as- } \\
\begin{array}{l}\text { sessment (detection bias) } \\
\text { All outcomes }\end{array}\end{array} \quad$ Unclear risk & $\begin{array}{l}\text { Quote: "A telephone follow-up } 6-15 \text { months after completion of the study, and } \\
\text { prior to breaking the randomisation code was made." }\end{array}$ \\
$\begin{array}{l}\text { Comment: Although this suggests the outcome assessor was unaware of the } \\
\text { treatment allocation at } 6 \text { to } 15 \text { months follow up, this domain was judged to } \\
\text { be unclear as there was a definite report of the outcome assessor being blind- } \\
\text { ed. }\end{array}$ \\
\hline
\end{tabular}


Savin 1990b (Continued)

Incomplete outcome data High risk Quote: "Thirty-six participants were entered into the study though only 28 (attrition bias) were included in the analysis of efficacy."

All outcomes

Comment: The reasons for the dropout of 2 participants were given; the remaining 6 participants were not accounted for (attrition rate was $22 \%$ ).

Selective reporting (re- Low risk porting bias)

Comment: The study protocol was not available. However, the outcomes stated in the methods of the report were all described in the results and discussion.

Other bias Low risk Comment: The study appeared to be free from other sources of bias.

Smith 2001

\begin{tabular}{ll}
\hline Methods & This was an open-label RCT. \\
\hline Participants & The treatment setting was multicentre. \\
& There were 27 participants in the initial sample. \\
& The total evaluable sample was 17 participants (group $1=10$ participants; group $2=7$ participants). \\
& Exclusion criteria of the trial \\
- Negative culture & Minimum level of clinical disease \\
- Systemic antifungal therapy within 6 weeks of screening \\
- Topical therapy within 2 weeks of screening \\
- HIV-Participants \\
- Group 1 : terbinafine 250 mg once daily for 2 weeks \\
- Group 2: terbinafine 250 mg once daily for 4 weeks
\end{tabular}

Outcomes

\section{Primary outcomes of the trial}

1. Cure, demonstrated by negative results on microscopy and culture

\section{Secondary outcomes of the trial}

1. Clinical disease score reported, based on erythema, pruritus, scaling of the skin, pustules, incrustation, vesiculation

2. Adverse events

Notes

Pharmaceutical involvement of the co-authors was declared; however, funding was not addressed.

\section{Risk of bias}

\begin{tabular}{lll}
\hline Bias & Authors' judgement & Support for judgement \\
\hline $\begin{array}{l}\text { Random sequence genera- } \\
\text { tion (selection bias) }\end{array}$ & Unclear risk & Comment: The method of randomisation was not reported. \\
\hline $\begin{array}{l}\text { Allocation concealment } \\
\text { (selection bias) }\end{array}$ & Unclear risk & Comment: The authors did not report how allocation was concealed. \\
\hline
\end{tabular}


Smith 2001 (Continued)
Blinding of participants
High risk
Quote: "...open label." and personnel (perfor-
Comment: Participants were not blinded; they were aware of which treatment mance bias)
All outcomes arm they were allocated.

\begin{tabular}{|c|c|c|}
\hline $\begin{array}{l}\text { Blinding (performance } \\
\text { bias and detection bias) } \\
\text { All outcomes }\end{array}$ & High risk & $\begin{array}{l}\text { Comment: There was no report regarding who allocated treatment/provided } \\
\text { medication. }\end{array}$ \\
\hline
\end{tabular}

\begin{tabular}{|c|c|c|}
\hline $\begin{array}{l}\text { Blinding of outcome as- } \\
\text { sessment (detection bias) } \\
\text { All outcomes }\end{array}$ & High risk & $\begin{array}{l}\text { Quote: "...open label." } \\
\text { Comment: The outcome assessors were not blinded. }\end{array}$ \\
\hline
\end{tabular}

\begin{tabular}{ll}
\hline $\begin{array}{l}\text { Incomplete outcome data } \\
\text { (attrition bias) }\end{array}$ & High risk \\
$\begin{array}{l}\text { All outcomes } \\
\text { Quote: "27 HIV-positive participants were enrolled in the study... ten partici- } \\
\text { pants subsequently were excluded because of negative initial culture results } \\
(\mathrm{n}=9) \text { or loss to follow up }(\mathrm{n}=1) . "\end{array}$ \\
$\begin{array}{l}\text { Comment: Those lost to follow up or excluded were accounted for. The attri- } \\
\text { tion rate was } 37 \% \text {. An intention-to-treat analysis was done. }\end{array}$
\end{tabular}

\begin{tabular}{|c|c|c|}
\hline $\begin{array}{l}\text { Selective reporting (re- } \\
\text { porting bias) }\end{array}$ & Low risk & $\begin{array}{l}\text { Comment: The study protocol was not available. However, the outcomes stat- } \\
\text { ed in the methods of the report were all described in the results and discus- } \\
\text { sion. }\end{array}$ \\
\hline \multirow[t]{2}{*}{ Other bias } & High risk & $\begin{array}{l}\text { Quote: "There were no differences in baseline demographics or disease char- } \\
\text { acteristics except for the duration of target infection. The mean duration was } \\
\text { less than half as long for the 2-week group compared to the 4-week group (151 } \\
\text { weeks versus } 376 \text { weeks)." }\end{array}$ \\
\hline & & $\begin{array}{l}\text { Comment: The duration of infection at baseline was substantially different for } \\
\text { the } 2 \text { groups. }\end{array}$ \\
\hline
\end{tabular}

\section{Svejgaard 1998}

\begin{tabular}{ll}
\hline Methods & This was an open-label trial. \\
\hline Participants & The treatment setting was multicentre. \\
& There were 72 participants in the initial sample (moccasin type tinea pedis). \\
& The total evaluable sample was 69 participants (group $1=34$ participants; group $2=35$ participants).
\end{tabular}

\section{Exclusion criteria of the trial}

- No systemic agent 6 months before the start of the study

\begin{tabular}{ll}
\hline Interventions & Group 1: itraconazole 200 mg taken twice daily for 1 week \\
\hline Outcomes & Group 2: placebo taken twice daily for 1 week \\
\hline & Primary outcomes of the trial \\
1. Cure, demonstrated by negative results on microscopy and no growth of dermatophyte in culture \\
Secondary outcomes of the trial \\
1. Clinical signs and symptoms: exudation, erythema, scaling, vesicular, pustules, crusting, pruritus, \\
itching, burning \\
2. Clinical global evaluation was reported \\
3. Adverse events (number of events)
\end{tabular}


Svejgaard 1998 (Continued)

Notes
Funding was supplied by a pharmaceutical company. Additionally, co-authors of the paper were affiliated to the company.

\section{Risk of bias}

\begin{tabular}{lll}
\hline Bias & Authors' judgement & Support for judgement \\
\hline $\begin{array}{l}\text { Random sequence genera- } \\
\text { tion (selection bias) }\end{array}$ & Unclear risk & Comment: The method of randomisation was not reported. \\
\hline
\end{tabular}

Allocation concealment Unclear risk Comment: There was no mention of allocation concealment.
(selection bias)

\begin{tabular}{|c|c|c|}
\hline $\begin{array}{l}\text { Blinding of participants } \\
\text { and personnel (perfor- } \\
\text { mance bias) }\end{array}$ & Unclear risk & $\begin{array}{l}\text { Quote: "Double blind..." } 72 \text { participants "were treated with itraconazole } \\
\text { ( } 200 \mathrm{mg} \text { twice daily) or placebo for } 1 \text { week with an } 8 \text { week treatment free follow } \\
\text { up period". }\end{array}$ \\
\hline
\end{tabular}

mance bias)

All outcomes

\begin{tabular}{|c|c|c|}
\hline $\begin{array}{l}\text { Blinding (performance } \\
\text { bias and detection bias) }\end{array}$ & Unclear risk & $\begin{array}{l}\text { Comment: There was no report regarding whether the treatment provider was } \\
\text { blinded. }\end{array}$ \\
\hline
\end{tabular}

All outcomes

Comment: Participants received active treatment or a placebo. It was not specifically stated that the participants were blinded nor was it clear which placebo regimen or appearance of treatment the placebo group received. Whilst the authors reported the trial to be 'double-blind', it was not reported who was blinded. Therefore, this domain was judged to be at unclear risk.

\begin{tabular}{|c|c|c|}
\hline $\begin{array}{l}\text { Blinding of outcome as- } \\
\text { sessment (detection bias) } \\
\text { All outcomes }\end{array}$ & Unclear risk & Comment: The authors did not report if the outcome assessor was blinded. \\
\hline $\begin{array}{l}\text { Incomplete outcome data } \\
\text { (attrition bias) } \\
\text { All outcomes }\end{array}$ & High risk & $\begin{array}{l}\text { Comment: } 1 \text { participant was recruited and then not randomised; } 22 \text { partici- } \\
\text { pants withdrew (adverse event and insufficient response); and } 1 \text { participant } \\
\text { was lost to follow up. The attrition rate was } 32 \% \text {, which was judged to be high } \\
\text { risk of bias. }\end{array}$ \\
\hline $\begin{array}{l}\text { Selective reporting (re- } \\
\text { porting bias) }\end{array}$ & Low risk & $\begin{array}{l}\text { Comment: The study protocol was not available. However, the outcomes stat- } \\
\text { ed in the methods of the report were all described in the results and discus- } \\
\text { sion. }\end{array}$ \\
\hline \multirow[t]{2}{*}{ Other bias } & Unclear risk & $\begin{array}{l}\text { Quote: "No significant inter group differences were seen, although the placebo } \\
\text { group had fewer men ( } 22 \text { versus } 30) . "\end{array}$ \\
\hline & & $\begin{array}{l}\text { Comment: Baselines characteristics were not comparable with regard to gen- } \\
\text { der. }\end{array}$ \\
\hline
\end{tabular}

Voravutinon 1993

\begin{tabular}{ll}
\hline Methods & This was a RCT. \\
\hline Participants & Treatment setting: hospital dermatology outpatients. \\
& There were 50 participants in the initial sample (tinea pedis). \\
& The total evaluable sample was 49 participants (group $1=23$ participants; group $2=26$ participants).
\end{tabular}

\section{Exclusion criteria of the trial}


Voravutinon 1993 (Continued)

- Not stated

$\begin{array}{ll}\text { Interventions } & \text { - Group 1: terbinafine } 250 \mathrm{mg} \text { taken once daily for } 2 \text { weeks } \\ & \text { - Group 2: itraconazole } 100 \mathrm{mg} \text { taken once daily for } 4 \text { weeks }\end{array}$

Outcomes

Primary outcomes of the trial

1. Cure, demonstrated by negative results on microscopy and no growth of dermatophyte in culture

\section{Secondary outcomes of the trial}

1. Clinical signs and symptoms: exudation, erythema, scaling, vesiculation, crusting, pruritus

2. Adverse events: number of participants (number of events)

Notes The source of funding was not reported.

\section{Risk of bias}

\begin{tabular}{lll}
\hline Bias & Authors' judgement & Support for judgement \\
\hline $\begin{array}{l}\text { Random sequence genera- } \\
\text { tion (selection bias) }\end{array}$ & Unclear risk & Comment: The method of randomisation was not reported. \\
\hline $\begin{array}{l}\text { Allocation concealment } \\
\text { (selection bias) }\end{array}$ & Unclear risk & Comment: The authors did not report how allocation was concealed. \\
\hline $\begin{array}{l}\text { Blinding of participants } \\
\text { and personnel (perfor- } \\
\text { mance bias) }\end{array}$ & Unclear risk & $\begin{array}{l}\text { Quote: "...double-blind." Participants "were randomly allocated to receive ei- } \\
\text { ther terbinafine 250mg once a day for two weeks or itraconazole 100mg once } \\
\text { daily for four weeks under double-blind conditions." }\end{array}$ \\
& $\begin{array}{l}\text { Comment: Participants received different regimens of medication. The au- } \\
\text { thors reported a 'double blind' design, but did not specifically state if it was } \\
\text { the participants who were blinded. Therefore, this domain was judged to be at } \\
\text { unclear risk. }\end{array}$
\end{tabular}

\begin{tabular}{|c|c|c|}
\hline $\begin{array}{l}\text { Blinding (performance } \\
\text { bias and detection bias) } \\
\text { All outcomes }\end{array}$ & Unclear risk & $\begin{array}{l}\text { Comment: There was no report regarding who allocated treatment or pro- } \\
\text { vided medication. It was not clear from the report whether the treatment } \\
\text { provider was blinded in this 'double blind' study. Therefore, this domain was } \\
\text { judged to be at unclear risk. }\end{array}$ \\
\hline
\end{tabular}

\begin{tabular}{lll}
\hline Blinding of outcome as- & Unclear risk & $\begin{array}{l}\text { Comment: Participants were assessed in the same manner; however, it was } \\
\text { nossment (detection bias) }\end{array}$ \\
All outcomes & judged to be at unclear risk.
\end{tabular}

Incomplete outcome data Low risk Quote: "50 participants entered the study." "The final analysis was based on (attrition bias) the data from 23 participants in the terbinafine group and 26 participants All outcomes $\quad$ treated with itraconazole."

Comment: 1 participant was lost at week 8 in the terbinafine group.

\begin{tabular}{lll}
\hline $\begin{array}{l}\text { Selective reporting (re- } \\
\text { porting bias) }\end{array}$ & Low risk & $\begin{array}{l}\text { Comment: The study protocol was not available. However, the outcomes stat- } \\
\text { ed in the methods of the report were all described in the results and discus- } \\
\text { sion. }\end{array}$ \\
\hline Other bias & Low risk & $\begin{array}{l}\text { Comment: The baseline demographics appeared to be equal. The trial ap- } \\
\text { peared to be free from other sources of potential bias. }\end{array}$
\end{tabular}


Widyanto 1993

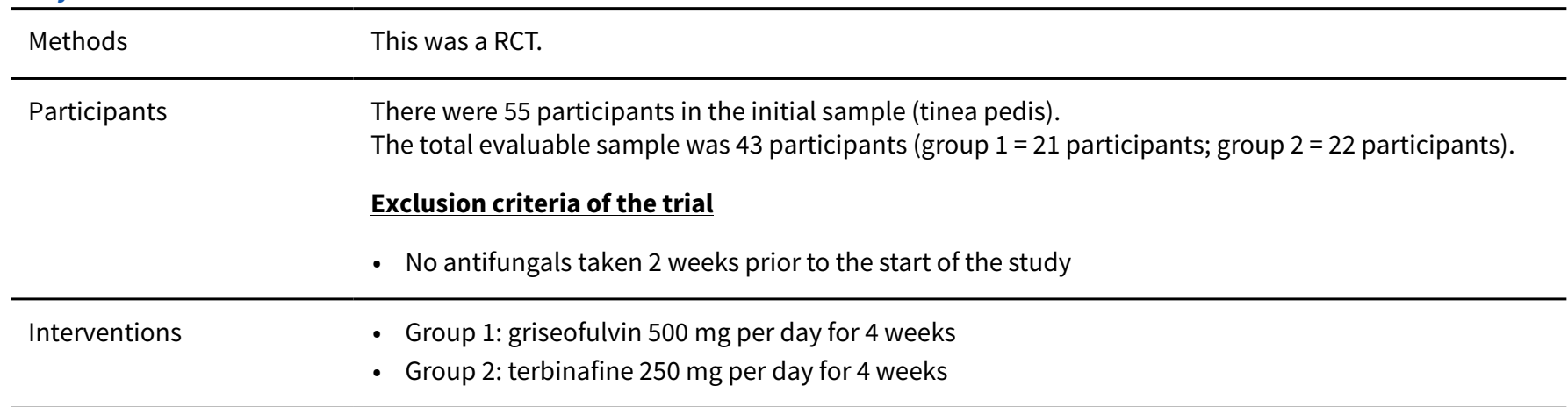

\section{Outcomes}

\section{Primary outcomes of the trial}

1. Cure, demonstrated by negative results on microscopy and no growth of dermatophyte in culture

\section{Secondary outcomes of the trial}

1. Clinical signs and symptoms: erythema, vesiculation, pustules, crusting, pruritus, maceration, squama

2. Adverse events

\begin{tabular}{ll}
\hline Notes & - \\
\hline Risk of bias
\end{tabular}

\begin{tabular}{lll}
\hline Bias Authors' judgement Support for judgement \\
\hline
\end{tabular}

Random sequence genera- Unclear risk tion (selection bias)
Quote: Participants "were randomly assigned to treatment with either oral terbinafine $250 \mathrm{mg}$ or griseofulvin 500mg".

Comment: The method of randomisation was not reported.

Allocation concealment $\quad$ Unclear risk
(selection bias)

\begin{tabular}{|c|c|c|}
\hline Blinding (performance & Unclear risk & Quote: "...double-blind." \\
\hline All outcomes & & $\begin{array}{l}\text { Comment: It was stated double-blind, but the report did not describe specifi- } \\
\text { cally who was blinded. Therefore, we judged this domain as unclear. }\end{array}$ \\
\hline
\end{tabular}

\begin{tabular}{lll}
\hline $\begin{array}{l}\text { Blinding of outcome as- } \\
\text { sessment (detection bias) } \\
\text { All outcomes }\end{array}$ & Unclear risk & $\begin{array}{l}\text { Comment: The study protocol was not available. However, the outcomes stat- } \\
\text { ed in the methods of the report were all described in the results and discus- } \\
\text { sion. }\end{array}$ \\
\hline $\begin{array}{l}\text { Incomplete outcome data } \\
\text { (attrition bias) }\end{array}$ & High risk & $\begin{array}{l}\text { Quote: "55 males with tinea pedis were treated, } 43 \text { of whom were eligible for } \\
\text { evaluation." }\end{array}$ \\
Cll outcomes & $\begin{array}{l}\text { Comment: No attempt was made to discuss why } 12 \text { participants were not in- } \\
\text { cluded in the analysis. }\end{array}$ \\
\hline
\end{tabular}


Widyanto 1993 (Continued)

Selective reporting (re- Low risk Comment: The study protocol was not available. However, the outcomes statporting bias) ed in the methods of the report were all described in the results and discussion.
Quote: "Demographic data showed that the two treatment groups were comparable with regard to age, race, location of lesions, aetiology and predisposing factors."

Comment: The baseline demographics appeared balanced. The trial appeared to be free from other potential sources of bias.

Yamanchi 2000

\begin{tabular}{ll}
\hline Methods & This was a RCT. \\
\hline Participants & There were 37 participants in the initial sample. \\
& The total evaluable sample was 37 participants (group 1 = 12 participants; group 2=14 participants; \\
group 3 = 11 participants). \\
Exclusion criteria of the trial \\
- Severe tinea pedis (as defined by symptom score) \\
- Participants currently using oral or topical steroids \\
- Use of any antifungal agent (oral or topical) within 1 month of the study \\
Study participants were members of staff at Morinaga Milk Industry Co., Ltd. \\
- Group 1: 2000 mg bovine lactoferrin \\
- Group 2: 600 mg bovine lactoferrin \\
\hline Interventions
\end{tabular}

Outcomes

\section{Primary outcomes of the trial}

1. Cure, demonstrated by negative results on microscopy and culture

\section{Secondary outcomes of the trial}

1. Dermatological improvement based on global clinical score (itching, erythema, vesicles/pustules, maceration/erosion, and scales)

2. Adverse events. Haematological Indices reported as significantly outside normal range

Notes The source of funding was not reported.

\section{Risk of bias}

\begin{tabular}{lll}
\hline Bias & Authors' judgement & Support for judgement \\
\hline $\begin{array}{l}\text { Random sequence genera- } \\
\text { tion (selection bias) }\end{array}$ & Unclear risk & Comment: The method of randomisation was not reported. \\
\hline $\begin{array}{l}\text { Allocation concealment } \\
\text { (selection bias) }\end{array}$ & Low risk & $\begin{array}{l}\text { Quote: "The study was carried out in a double-blind fashion and the ran- } \\
\text { domised code for allocation of subjects to each group was unknown to the in- } \\
\text { vestigators." }\end{array}$
\end{tabular}


Comment: Allocation concealment was judged to have been achieved because of the statement that the randomised code used for allocation was unknown to the investigator.
Blinding of participants Low risk Quote: "...double-blind." "Four test tablets, either LF low dose tablets (75mg and personnel (perfor- tablets), LF high dose tablets (250mg tablets) or placebo tablets were adminismance bias)

All outcomes

tered to each subject twice a day for 8 weeks."

Comment: Participants received the same tablet regimen and number of tablets. Whilst it was not specifically stated that the participants were blinded, the study was reported to be 'double-blind'. It was judged that the participants were blinded; therefore, this domain was judged to be at low risk.

\begin{tabular}{|c|c|c|}
\hline $\begin{array}{l}\text { Blinding (performance } \\
\text { bias and detection bias) }\end{array}$ & Unclear risk & $\begin{array}{l}\text { Quote: "The LF in tablets were obtained from Milei GmbH (Leutkirch } \\
\text { Adrazhofen, Germany)." }\end{array}$ \\
\hline
\end{tabular}

All outcomes

Comment: There was no report regarding who allocated treatment, though the origin of the tablets was reported. It was not clear from the report whether the treatment provider was blinded in this 'double blind' study. Therefore, we judged this to be at unclear risk.

\begin{tabular}{|c|c|c|}
\hline $\begin{array}{l}\text { Blinding of outcome as- } \\
\text { sessment (detection bias) }\end{array}$ & Unclear risk & $\begin{array}{l}\text { Comment: Participants were assessed in the same manner; however, it was } \\
\text { unclear if the outcome assessor was blinded. }\end{array}$ \\
\hline
\end{tabular}

All outcomes

\begin{tabular}{|c|c|c|}
\hline $\begin{array}{l}\text { Incomplete outcome data } \\
\text { (attrition bias) } \\
\text { All outcomes }\end{array}$ & Low risk & $\begin{array}{l}\text { Quote: "In the } 37 \text { subjects there were no adverse events and no subject with- } \\
\text { drew from the study because of an adverse effect." } \\
\text { Comment: No data were lost. }\end{array}$ \\
\hline $\begin{array}{l}\text { Selective reporting (re- } \\
\text { porting bias) }\end{array}$ & Low risk & $\begin{array}{l}\text { Comment: The study protocol was not available. However, the outcomes stat- } \\
\text { ed in the methods of the report were all described in the results and discus- } \\
\text { sion. }\end{array}$ \\
\hline Other bias & Unclear risk & $\begin{array}{l}\text { Comment: } 35 \text { participants were men, and } 2 \text { participants were women. All par- } \\
\text { ticipants were workers of Morinaga Milk Industry Co., Ltd. It was unclear if this } \\
\text { cluster bias had any impact on the study. We identified no other sources of po- } \\
\text { tential bias. }\end{array}$ \\
\hline
\end{tabular}

\section{Characteristics of excluded studies [ordered by study ID]}

\begin{tabular}{ll}
\hline Study & Reason for exclusion \\
\hline Baldari 2000 & Dermatomycoses were studied; separate data for tinea pedis was not presented. \\
\hline Barnetson 1998 & This trial combined data for topical and oral treatments. \\
\hline Bortolussi 2007 & This was a review article regarding infections in children. \\
\hline Bortolussi 2008 & This was a review article regarding infections in children. \\
\hline Brugmans 1969 & Data were presented for topical treatment only. \\
\hline Decroix 2008 & This was a CCT and not a RCT. \\
\hline Degreef 1987 & This trial combined data for foot and hand infections. \\
\hline \hline
\end{tabular}




\begin{tabular}{|c|c|}
\hline Study & Reason for exclusion \\
\hline Del Palacio 1993 & This trial combined data for foot and hand infections. \\
\hline Gupta 1999 & This was not a randomised controlled trial. \\
\hline Hay 1991 & This combined data for foot and hand infections. \\
\hline Humphreys 2004 & This was a review article. \\
\hline Jolly 1983 & This trial combined data. \\
\hline Lachapelle 1992 & $\begin{array}{l}\text { This trial combined data for foot and hand infections; separate data for tinea pedis were not avail- } \\
\text { able. }\end{array}$ \\
\hline Legendre 1980 & There were not enough data reported, and the length of treatment time was unclear. \\
\hline Lynfield 1974 & This trial combined data for topical and oral treatments. \\
\hline Markova 2002 & This was a review article. \\
\hline Russell 1960 & There was no microscopy and culture as an outcome. \\
\hline Schuller 1998 & This trial combined data for foot and hand infections. \\
\hline Stengel 1995 & Separate data on tinea pedis was not presented. \\
\hline Tausch 1998 & This trial combined data for foot and hand infections. \\
\hline Van Hecke 1988 & This trial combined data for foot and hand infections. \\
\hline White 1991 & This trial combined data for foot and hand infections. \\
\hline Wishart 1994 & This trial combined data for foot and hand infections. \\
\hline Won 1993 & There was no microscopy and culture as an outcome. \\
\hline Yao 1999 & This was a CCT and not a RCT. \\
\hline
\end{tabular}

Characteristics of studies awaiting assessment [ordered by study ID]

\begin{tabular}{ll}
\hline Decroix 1995 & Please see the Notes cell. \\
\hline Methods & Please see the Notes cell. \\
\hline Interventions & Please see the Notes cell. \\
\hline Outcomes & Please see the Notes cell. \\
\hline Notes & We are awaiting the retrieval of the full text of this paper. \\
\hline
\end{tabular}


Characteristics of ongoing studies [ordered by study ID]

\section{NCT00509275}

Trial name or title

Methods

A Phase Ib, Randomized, Double Blind, Placebo Controlled Study to Investigate the Pharmacokinetics, Safety and Efficacy of 3 Different Doses of W0027 and Placebo Capsules in Subjects With

Clinically and Mycologically Proven MTTP

In this phase Ib, multicentre, randomised, double-blind, placebo-controlled parallel-group study, 120 participants with moccasin type tinea pedis (MTTP) will be enrolled at approximately 11 centres in the US, Canada, and Australia. The primary objective of the study is to assess the participant response to 3 W0027 regimens in subjects with MTTP. Secondary objectives include assessment of the safety, tolerability, and skin and nail pharmacokinetics to the 3 Albaconazole regimens.

\begin{tabular}{ll}
\hline Participants & 120 subjects with moccasin type tinea pedis \\
\hline Interventions & $\cdot 3$ different doses of W0027 and placebo \\
\hline
\end{tabular}

\section{Primary outcomes of the trial}

1. To assess the subject response to 3 W0027 regimens in subjects with MTTP (time frame: week 8 )

\section{Secondary outcomes of the trial}

1. To assess the safety and tolerability of 3 W0027 regimens in subjects with MTTP

2. To assess skin and nail pharmacokinetics of 3 Albaconazole doses in subjects with MTTP

\begin{tabular}{ll}
\hline Starting date & July 2007 (Completed) \\
\hline Contact information & Lynda Spelman, MD, Principal Investigator, South East Dermatology, South East Dermatology, Cari- \\
& na QLD 4152, Australia \\
& Michael Freeman, MD, Principal Investigator, The Skin Centre, Benowa QLD 4217, Australia \\
& Peter Foley, MD, Principal Investigator, Skin and Cancer Foundation, Carlton VIC 3053, Australia \\
& Stephen Shumack, MD, Principal Investigator, St George Dermatology and Skin Cancer Centre, \\
& Kogarah NSW 2217, Australia \\
& Warren Weightman, MD, Principal Investigator, Dermatology on Ward, North Adelaide SA 5006, \\
& Australia \\
& Debra Breneman, MD, Principal Investigator, University Dermatology Consultants, Inc., Cincinnati, \\
& OH, 45219, US \\
& Eduardo Tschen, MD, Principal Investigator, Albuquerque, NM 87106, US \\
& Yves Poulin, MD, Principal Investigator, Centre de Dermatologie, Quebec, QC, G1V 4X7, Canada \\
& David Gratton, MD, Principal Investigator, International Dermatology Research Inc., Montreal, QC, \\
& H3H 1V4, Canada \\
Wayne Gulliver Gulliver, MD, Principal Investigator, NewLab Clinical Research, St. John's, NF, A1B \\
3E1, Canada \\
Steven Grekin, MD, Principal Investigator, 13450 East 12 Mile Road, Warren, MI 48088, US \\
Joseph Fowler, MD, Principal Investigator, Dermatology Specialists, 501 South Second Street, \\
Louisville, KY 40202, US
\end{tabular}

Notes

The trial was sponsored by Stiefel, a GlaxoSmithKline (GSK) company.

We obtained information from http://clinicaltrials.gov/ on 2 February 2012. NCT00509275

\section{DATA AND ANALYSES}


Comparison 1. Antifungal versus placebo

\begin{tabular}{lllll}
\hline Outcome or subgroup title & $\begin{array}{l}\text { No. of } \\
\text { studies }\end{array}$ & $\begin{array}{l}\text { No. of } \\
\text { partici- } \\
\text { pants }\end{array}$ & Statistical method & Effect size \\
\hline $\begin{array}{l}1 \text { Cured (terbinafine } 250 \mathrm{mg} / \text { day versus } \\
\text { placebo) }\end{array}$ & 1 & Risk Ratio (M-H, Fixed, 95\% Cl) & Totals not selected \\
\hline $\begin{array}{llll}1.1 \text { week } 8 \\
2 \text { Cured (itraconazole } 400 \mathrm{mg} / \text { day versus } \\
\text { placebo) }\end{array}$ & 1 & Risk Ratio (M-H, Fixed, 95\% Cl) & $0.0[0.0,0.0]$ \\
\hline 2.1 week 9 & 1 & Risk Ratio (M-H, Fixed, 95\% Cl) & Totals not selected \\
\hline
\end{tabular}

Analysis 1.1. Comparison 1 Antifungal versus placebo, Outcome 1 Cured (terbinafine $250 \mathrm{mg} /$ day versus placebo).

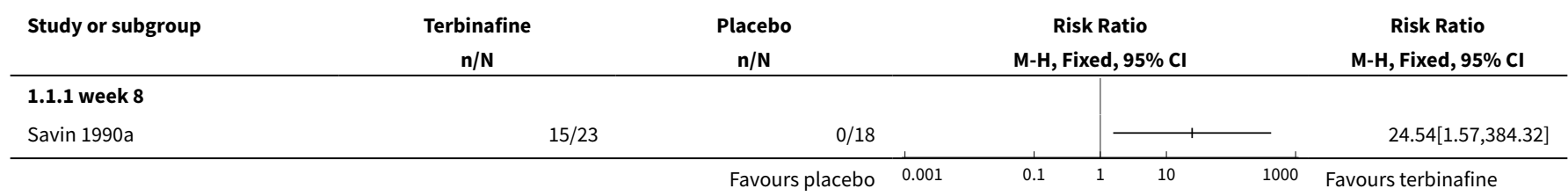

Analysis 1.2. Comparison 1 Antifungal versus placebo, Outcome 2 Cured (itraconazole $400 \mathrm{mg} /$ day versus placebo).

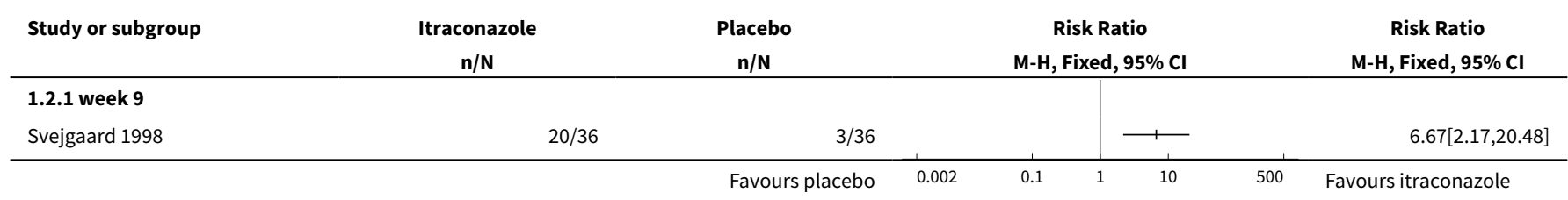

\section{Comparison 2. Different types of antifungals}

\begin{tabular}{lllll}
\hline Outcome or subgroup title & $\begin{array}{l}\text { No. of } \\
\text { studies }\end{array}$ & $\begin{array}{l}\text { No. of } \\
\text { partici- } \\
\text { pants }\end{array}$ & Statistical method & Effect size \\
\hline $\begin{array}{l}1 \text { Cured (terbinafine } 250 \\
\text { mg/day versus itraconazole } \\
100 \mathrm{mg} / \text { day) }\end{array}$ & 4 & & Risk Ratio $(\mathrm{M}-\mathrm{H}$, Random, $95 \% \mathrm{Cl})$ & Subtotals only \\
\hline 1.1 week 4 & 1 & 44 & Risk Ratio (M-H, Random, $95 \% \mathrm{Cl})$ & $0.93[0.61,1.43]$ \\
\hline 1.2 week 8 & 2 & 166 & Risk Ratio (M-H, Random, $95 \% \mathrm{Cl})$ & $1.28[0.82,1.98]$ \\
\hline 1.3 week 12 plus & 1 & 129 & Risk Ratio $(\mathrm{M}-\mathrm{H}$, Random, $95 \% \mathrm{Cl})$ & $1.14[0.93,1.41]$ \\
\hline
\end{tabular}




\begin{tabular}{|c|c|c|c|c|}
\hline Outcome or subgroup title & $\begin{array}{l}\text { No. of } \\
\text { studies }\end{array}$ & $\begin{array}{l}\text { No. of } \\
\text { partici- } \\
\text { pants }\end{array}$ & Statistical method & Effect size \\
\hline $\begin{array}{l}1.4 \text { common treatment } \\
\text { length ( } 4 \text { weeks) }\end{array}$ & 3 & 222 & Risk Ratio (M-H, Random, 95\% Cl) & $1.07[0.92,1.25]$ \\
\hline $\begin{array}{l}2 \text { Cured (itraconazole } 100 \\
\mathrm{mg} / \text { day versus fluconazole } \\
50 \mathrm{mg} / \text { day) }\end{array}$ & 1 & & Risk Ratio (M-H, Fixed, 95\% Cl) & Totals not selected \\
\hline 2.1 week 10 & 1 & & Risk Ratio (M-H, Fixed, 95\% Cl) & $0.0[0.0,0.0]$ \\
\hline $\begin{array}{l}3 \text { Cured (fluconazole } 50 \mathrm{mg} / \\
\text { day versus ketoconazole } \\
200 \mathrm{mg} / \text { day) }\end{array}$ & 1 & & Risk Ratio (M-H, Fixed, 95\% Cl) & Totals not selected \\
\hline 3.1 week 7 & 1 & & Risk Ratio (M-H, Fixed, 95\% Cl) & $0.0[0.0,0.0]$ \\
\hline $\begin{array}{l}4 \text { Cured (ketaconazole } 200 \\
\text { mg/day versus griseofulvin } \\
1000 \text { mg/day) }\end{array}$ & 1 & & Risk Ratio (M-H, Fixed, 95\% Cl) & Totals not selected \\
\hline 4.1 week 8 & 1 & & Risk Ratio (M-H, Fixed, 95\% Cl) & $0.0[0.0,0.0]$ \\
\hline $\begin{array}{l}5 \text { Cured (terbinafine } 250 \mathrm{mg} \\
\text { versus griseofulvin } 500 \mathrm{mg} \text { ) }\end{array}$ & 2 & & Risk Ratio (M-H, Fixed, 95\% Cl) & Subtotals only \\
\hline 5.1 week 4 & 1 & 43 & Risk Ratio (M-H, Fixed, 95\% Cl) & $2.59[1.38,4.85]$ \\
\hline 5.2 week 8 & 1 & 28 & Risk Ratio (M-H, Fixed, 95\% Cl) & $1.94[1.12,3.36]$ \\
\hline 5.3 last outcome point & 2 & 71 & Risk Ratio (M-H, Fixed, 95\% Cl) & $2.26[1.49,3.44]$ \\
\hline $\begin{array}{l}6 \text { Cured (fluconazole } 150 \\
\mathrm{mg} / \text { week versus flucona- } \\
\text { zole } 50 \mathrm{mg} / \text { day) }\end{array}$ & 1 & & Risk Ratio (M-H, Fixed, 95\% Cl) & Totals not selected \\
\hline 6.1 week 10 & 1 & & Risk Ratio (M-H, Fixed, 95\% Cl) & $0.0[0.0,0.0]$ \\
\hline $\begin{array}{l}7 \text { Cured (terbinafine } \\
250 \mathrm{mg} / 2 \text { weeks versus } \\
\text { terbinafine } 250 \mathrm{mg} / 4 \\
\text { weeks) }\end{array}$ & 1 & & Risk Ratio (M-H, Fixed, 95\% Cl) & Totals not selected \\
\hline
\end{tabular}
Analysis 2.1. Comparison 2 Different types of antifungals, Outcome
1 Cured (terbinafine $250 \mathrm{mg} /$ day versus itraconazole $100 \mathrm{mg} /$ day).

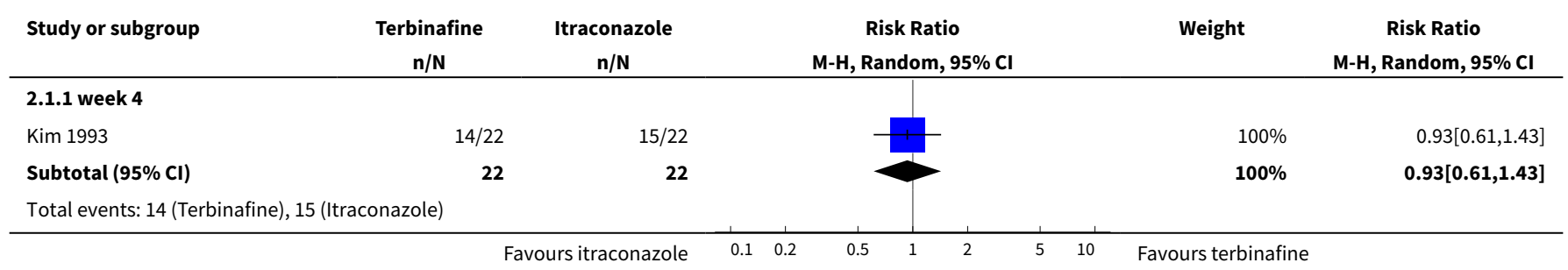




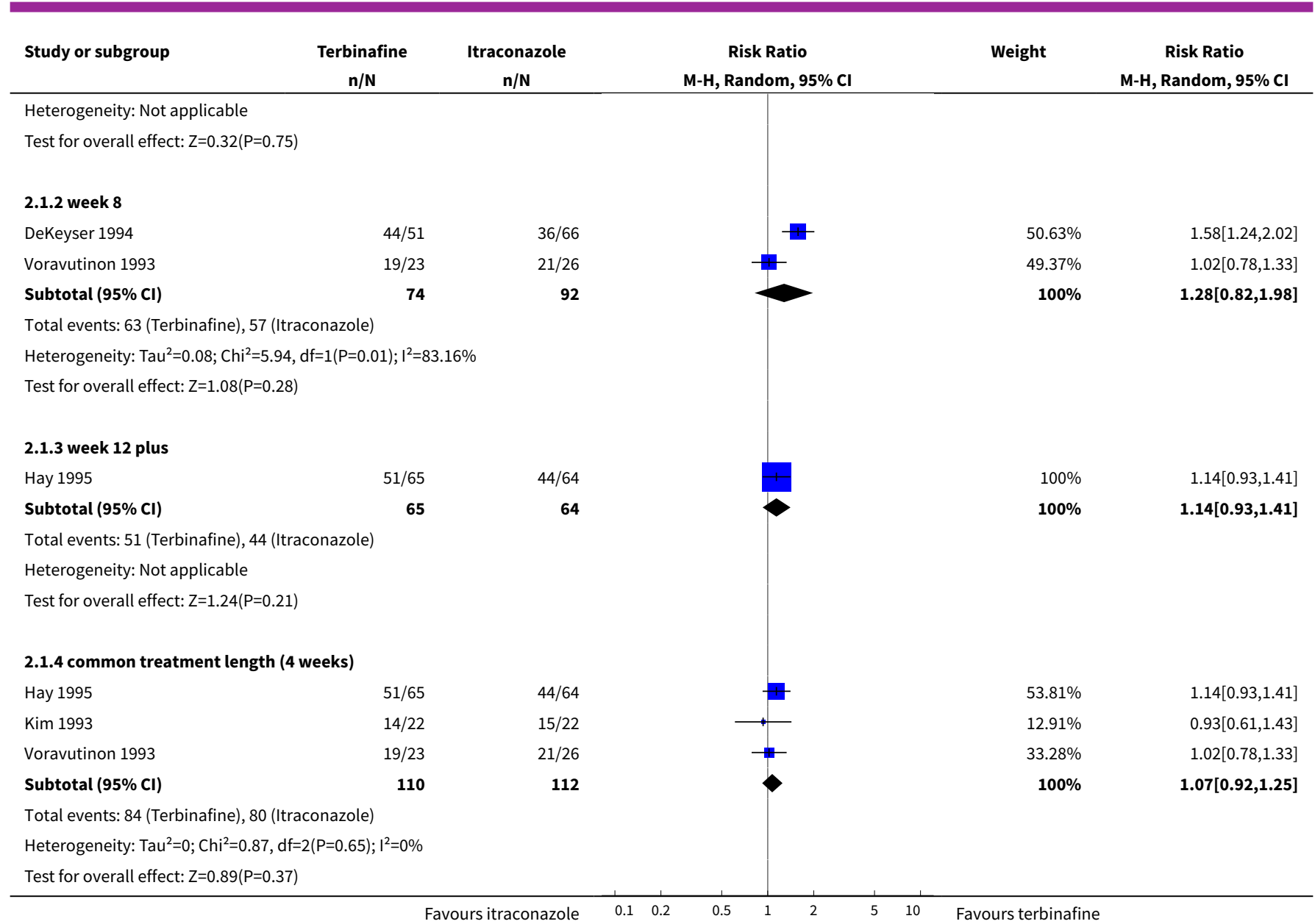

Analysis 2.2. Comparison 2 Different types of antifungals, Outcome 2 Cured (itraconazole $100 \mathrm{mg} /$ day versus fluconazole $50 \mathrm{mg} /$ day).

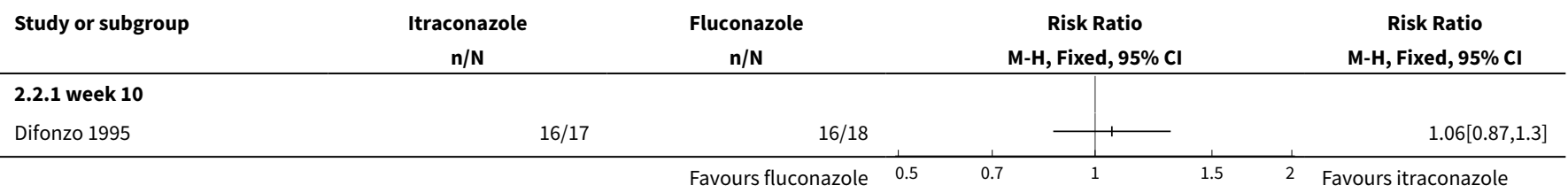

Analysis 2.3. Comparison 2 Different types of antifungals, Outcome 3 Cured (fluconazole $50 \mathrm{mg} /$ day versus ketoconazole $200 \mathrm{mg} /$ day).

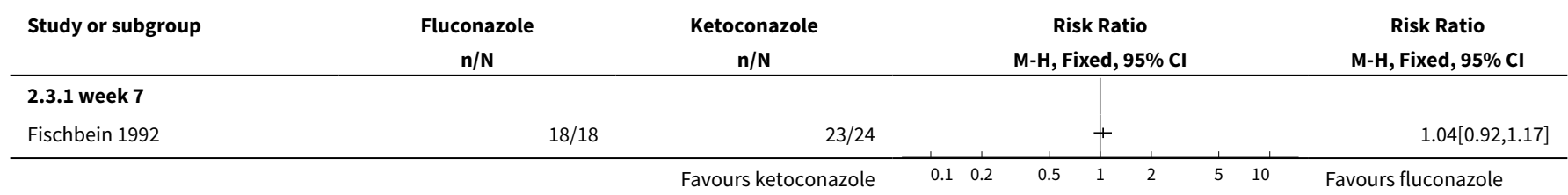


Analysis 2.4. Comparison 2 Different types of antifungals, Outcome 4 Cured (ketaconazole $200 \mathrm{mg} /$ day versus griseofulvin $1000 \mathrm{mg} /$ day).

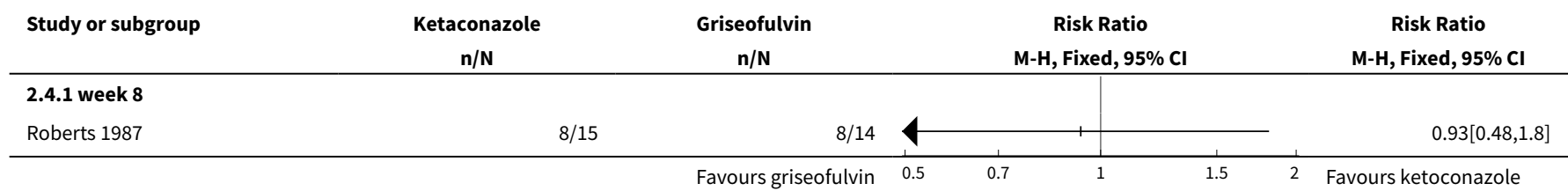

Analysis 2.5. Comparison 2 Different types of antifungals, Outcome 5 Cured (terbinafine $250 \mathrm{mg}$ versus griseofulvin $500 \mathrm{mg}$ ).

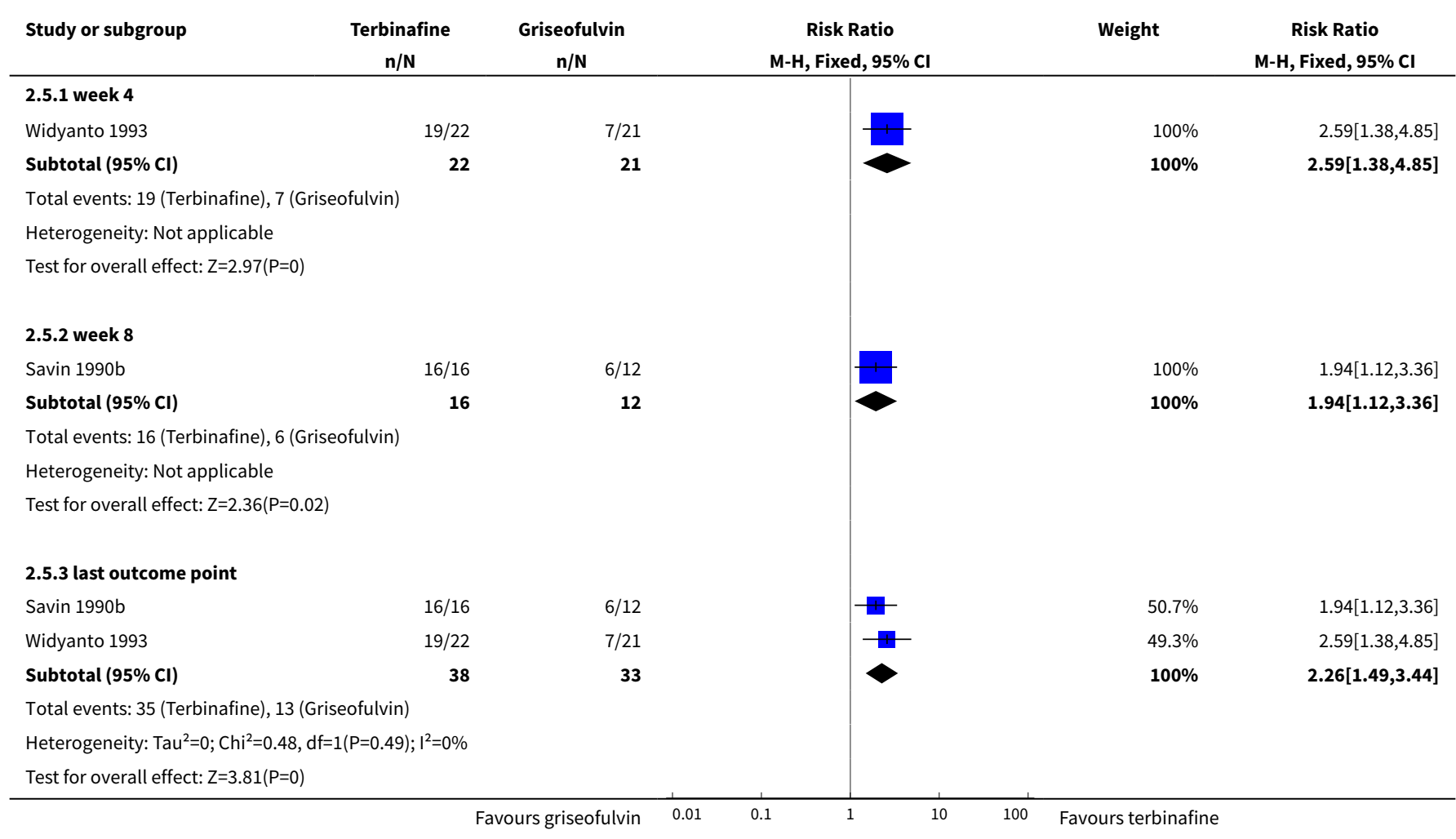

Analysis 2.6. Comparison 2 Different types of antifungals, Outcome 6 Cured (fluconazole $150 \mathrm{mg} /$ week versus fluconazole $50 \mathrm{mg} / \mathrm{day}$ ).

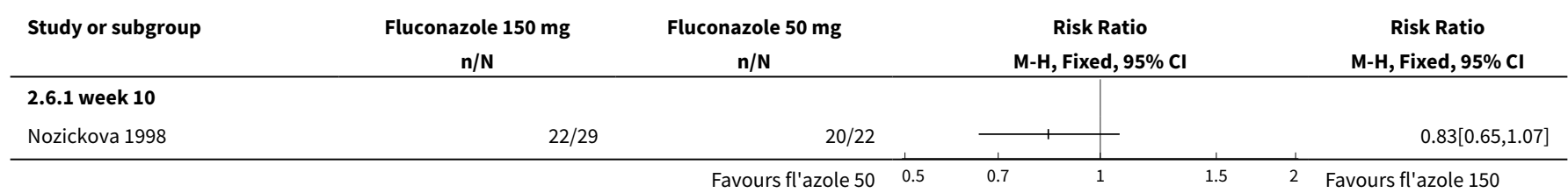


Analysis 2.7. Comparison 2 Different types of antifungals, Outcome 7

Cured (terbinafine $250 \mathrm{mg} / 2$ weeks versus terbinafine $250 \mathrm{mg} / 4$ weeks).

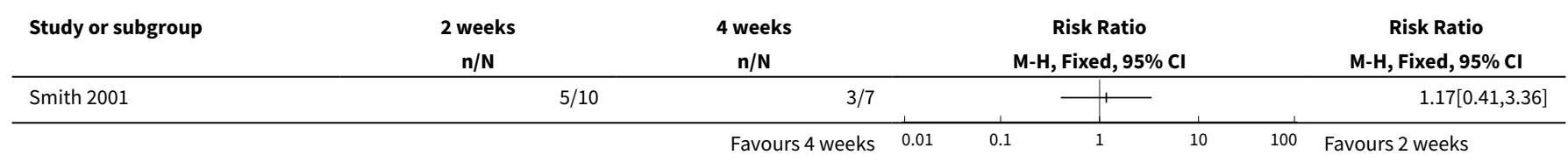

\section{Comparison 3. Presentation of tinea pedis}

\begin{tabular}{llllll}
\hline Outcome or subgroup title & $\begin{array}{l}\text { No. of } \\
\text { studies }\end{array}$ & $\begin{array}{l}\text { No. of } \\
\text { partici- } \\
\text { pants }\end{array}$ & Statistical method & Effect size \\
\hline 1 Plantar tinea pedis & 2 & 173 & Risk Ratio $(\mathrm{M}-\mathrm{H}, \mathrm{Random}, 95 \% \mathrm{Cl})$ & $1.10[0.91,1.32]$ \\
\hline 2 Mixed distribution of tinea pedis & 2 & 166 & Risk Ratio $(\mathrm{M}-\mathrm{H}$, Random, $95 \% \mathrm{Cl})$ & $1.28[0.82,1.98]$ \\
\hline
\end{tabular}

Analysis 3.1. Comparison 3 Presentation of tinea pedis, Outcome 1 Plantar tinea pedis.

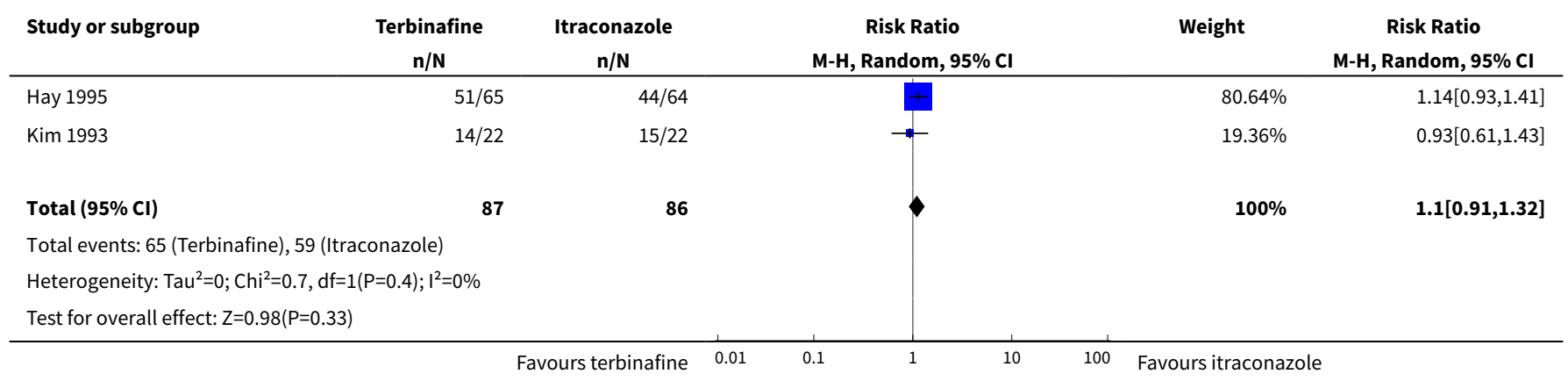

Analysis 3.2. Comparison 3 Presentation of tinea pedis, Outcome 2 Mixed distribution of tinea pedis.

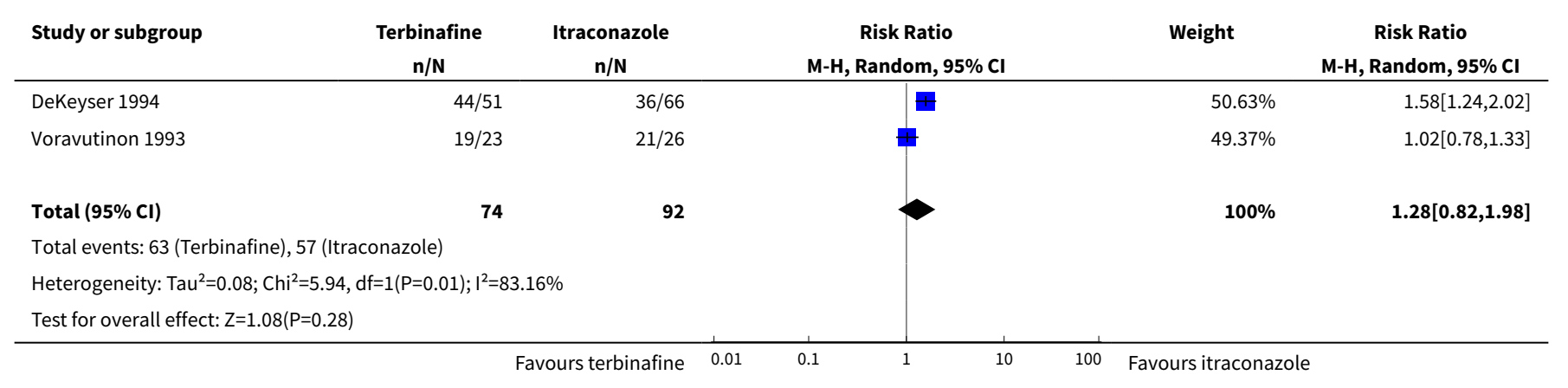




\section{Comparison 4. Adverse events}

\begin{tabular}{lllll}
\hline Outcome or subgroup title & $\begin{array}{l}\text { No. of } \\
\text { studies }\end{array}$ & $\begin{array}{l}\text { No. of par- } \\
\text { ticipants }\end{array}$ & $\begin{array}{l}\text { Statistical } \\
\text { method }\end{array}$ & Effect size \\
\hline 1 Summary of adverse events reported for trials of tinea pedis & Other data & No numeric data \\
\hline
\end{tabular}

Analysis 4.1. Comparison 4 Adverse events, Outcome 1 Summary of adverse events reported for trials of tinea pedis.

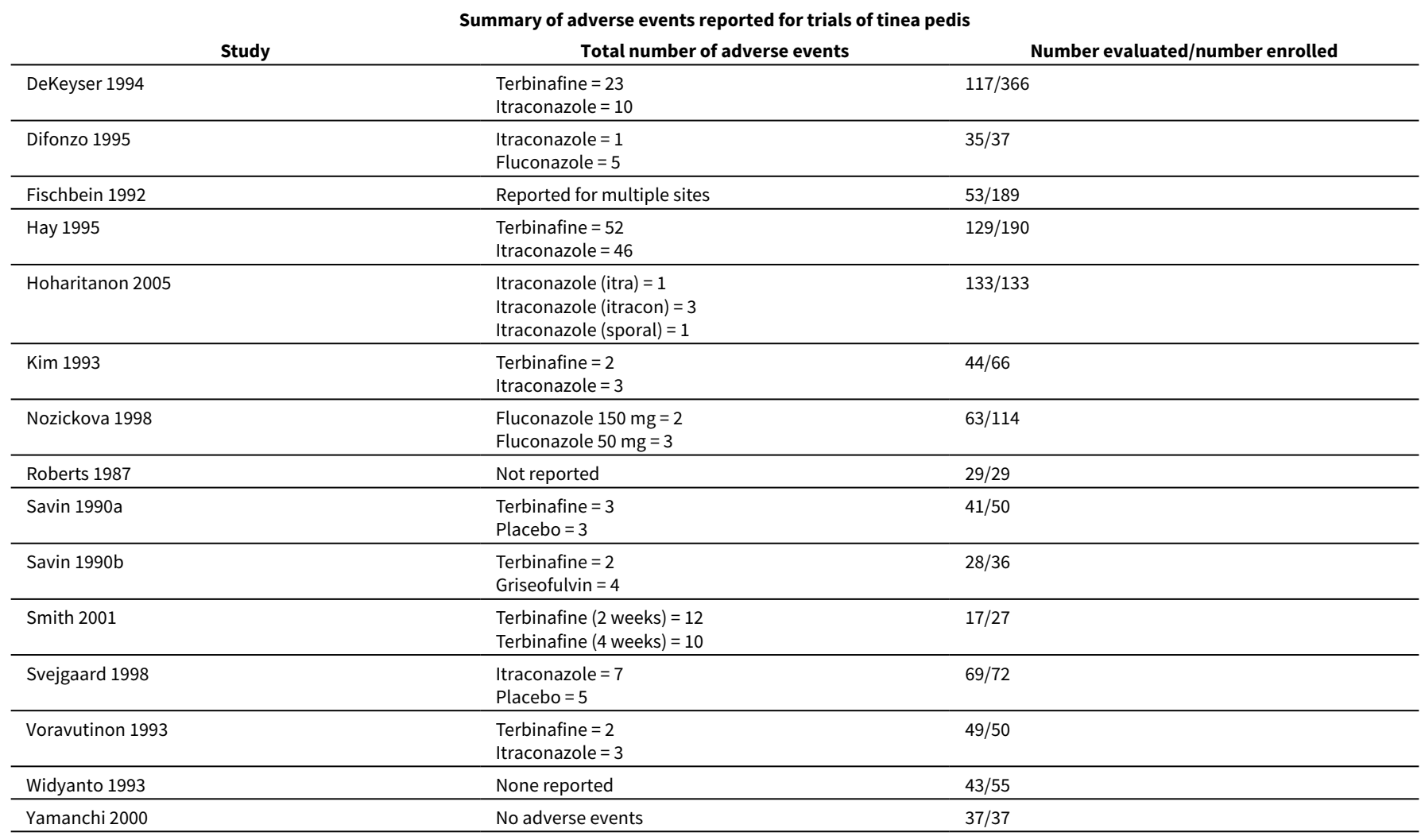

\section{AP PE N D I C E S}

\section{Appendix 1. Skin Group Specialised Register search strategy}

(tinea and (foot or feet)) or "tinea pedis" or "athlete* foot" or "moccasin foot" or "tinea pedum" or "tinea pectis" or ((foot or feet) and ringworm) or ("fungal infection*" and (foot or feet))

\section{Appendix 2. CENTRAL (Cochrane Library) search strategy}

\#1 MeSH descriptor Tinea Pedis explode all trees

\#2 "athlete ${ }^{\star}$ foot" or "moccasin foot" or "tinea pedum" or "tinea pectis" or "tinea pedis"

\#3 "fungal infection*" and (foot or feet)

\#4 (ringworm) and (foot or feet)

$\# 5$ (tinea) and (foot or feet)

\#6 (\#1 OR \#2 OR \#3 OR \#4 OR \#5) 


\section{Appendix 3. MEDLINE (OVID) search strategy}

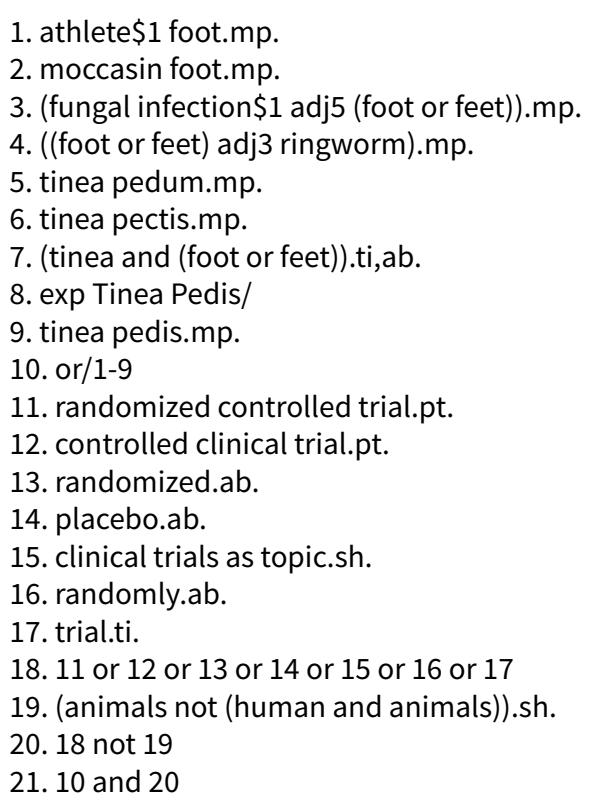

\section{Appendix 4. EMBASE (OVID) search strategy}

1. exp tinea pedis/

2. tinea pedis.ti,ab.

3. athlete $\$ 1$ foot.mp.

4. moccasin foot.mp.

5. (fungal infection $\$ 1$ adj5 (foot or feet)).mp.

6. ((foot or feet) adj3 ringworm).mp.

7. tinea pedum.mp.

8. tinea pectis.mp.

9. (tinea and (foot or feet)).ti,ab.

10. or/1-9

11. random\$.mp.

12. factorial\$.mp.

13. (crossover\$ or cross-over\$).mp.

14. placebo\$.mp. or PLACEBO/

15. (doubl\$ adj blind\$).mp. [mp=title, abstract, subject headings, heading word, drug trade name, original title, device manufacturer, drug manufacturer, device trade name, keyword]

16. (singl\$ adj blind\$).mp. [mp=title, abstract, subject headings, heading word, drug trade name, original title, device manufacturer, drug manufacturer, device trade name, keyword]

17. (assign\$ or allocat\$).mp.

18. volunteer\$.mp. or VOLUNTEER/

19. Crossover Procedure/

20. Double Blind Procedure/

21. Randomized Controlled Trial/

22. Single Blind Procedure/

23. 11 or 12 or 13 or 14 or 15 or 16 or 17 or 18 or 19 or 20 or 21 or 22

24. 10 and 23

\section{Appendix 5. CINAHL (EBSCO) search strategy}

S1 (MH "Clinical Trials+")

S2 PT clinical trial

S3 TX (clinic* $n 1$ trial $^{*}$ )

S4 (MH "Random Assignment")

S5 TX random* ${ }^{\star}$ allocat*

S6 TX placebo*

S7 (MH "Placebos")

S8 (MH "Quantitative Studies") 
S9 TX allocat* random*

S10 "randomi\#ed control* trial $^{* "}$

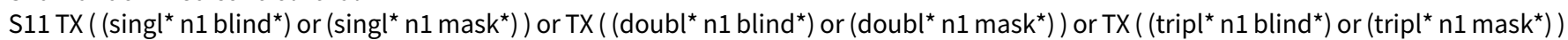
or TX ( (trebl* $n 1$ blind $\left.{ }^{\star}\right)$ or (trebl* $n 1$ mask $\left.^{\star}\right)$ )

$\mathrm{S} 12 \mathrm{~S} 1$ or $\mathrm{S} 2$ or S3 or S4 or S5 or S6 or S7 or S8 or S9 or S10 or S11

S13 TI "tinea pedis" OR AB "tinea pedis"

S14 TI "tinea pedum" OR AB "tinea pedum"

S15 TI "tinea pectis" OR AB "tinea pectis"

S16 TI "athlete* foot" OR AB "athlete* foot"

S17 TI "moccasin foot" OR AB "moccasin foot"

$\mathrm{S} 18 \mathrm{~S} 13$ or $\mathrm{S} 14$ or S15 or S16 or S17

S19 S12 and S18

\section{Appendix 6. Searches undertaken for the original version of this review but not repeated for this update}

Wer searched CAB-Health 1973 to December 1997 and Healthstar 1975 to December 1997. In addition the on-line versions of DARE, NHS Economic Evaluation Database and EconLit were screened to January 2000. The Internet was searched, using the Yahoo Search Engine, to identify any further useful sources of information. The following podiatry journals that are not listed in the electronic databases were hand searched: Foot; Journal of British Podiatric Medicine; Journal of the American Podiatry Association. The British Journal of Dermatology has recently been partly hand searched and the results were obtained from the Cochrane Skin Group. A search for unpublished or unlisted studies was made by contacting all schools of podiatry in the UK with a request made for dissertation bibliographies. No studies were identified by this method. The pharmaceutical industry was contacted to request reports of further published and unpublished trials. Replies were received from several companies. However, no new trials were identified that had not already been sourced from the database searches.

\section{Appendix 7. 'Risk of bias' criteria}

\section{Was the allocation sequence randomly generated?}

\section{Low risk of bias}

The investigators describe a random component in the sequence generation process, such as referring to a random number table, using a computer random number generator, coin tossing, shuffling cards or envelopes, throwing dice, or the drawing of lots.

\section{High risk of bias}

The investigators describe a non-random component in the sequence generation process. Usually, the description would involve some systematic, non-random approach, for example, sequence generated by odd or even date of birth, sequence generated by some rule based on date (or day) of admission, or sequence generated by some rule based on hospital or clinic record number.

\section{Unclear}

Insufficient information about the sequence generation process to permit judgement of low or high risk of bias.

\section{Was the treatment allocation adequately concealed?}

\section{Low risk of bias}

Participants and investigators enrolling participants could not foresee assignment because one of the following, or an equivalent method, was used to conceal allocation: central allocation (including telephone, web-based, and pharmacy-controlled randomisation); sequentially-numbered drug containers of identical appearance; or sequentially-numbered, opaque, sealed envelopes.

\section{High risk of bias}

Participants or investigators enrolling participants could possibly foresee assignments and thus introduce selection bias, such as allocation based on using an open random allocation schedule (e.g. a list of random numbers); assignment envelopes were used without appropriate safeguards (e.g. if envelopes were unsealed or non opaque or not sequentially numbered); alternation or rotation; date of birth; case record number; any other explicitly unconcealed procedure.

\section{Unclear}

Insufficient information to permit judgement of low or high risk of bias. This is usually the case if the method of concealment is not described or not described in sufficient detail to allow a definite judgement, for example if the use of assignment envelopes is described, but it remains unclear whether envelopes were sequentially numbered, opaque and sealed. 
3. Blinding - was knowledge of the allocated interventions adequately prevented during the study?

\section{Low risk of bias}

Any one of the following.

- No blinding, but the review authors judge that the outcome and the outcome measurement are not likely to be influenced by lack of blinding.

- Blinding of participants and key study personnel ensured, and unlikely that the blinding could have been broken.

- Either participants or some key study personnel were not blinded, but outcome assessment was blinded and the non-blinding of others unlikely to introduce bias.

\section{High risk of bias}

Any one of the following.

- No blinding or incomplete blinding, and the outcome or outcome measurement is likely to be influenced by lack of blinding.

- Blinding of key study participants and personnel attempted, but likely that the blinding could have been broken.

- Either participants or some key study personnel were not blinded, and the non-blinding of others likely to introduce bias.

\section{Unclear}

Any one of the following.

- Insufficient information to permit judgement of low or high risk of bias.

- The study did not address this outcome.

\section{Were incomplete outcome data adequately addressed?}

\section{Low risk of bias}

Any one of the following.

- No missing outcome data.

- Reasons for missing outcome data unlikely to be related to true outcome (for survival data, censoring unlikely to be introducing bias).

- Missing outcome data balanced in numbers across intervention groups, with similar reasons for missing data across groups.

- For dichotomous outcome data, the proportion of missing outcomes compared with observed event risk not enough to have a clinically relevant impact on the intervention effect estimate.

- For continuous outcome data, plausible effect size (difference in means or standardised difference in means) among missing outcomes not enough to have a clinically relevant impact on observed effect size.

- Missing data have been imputed using appropriate methods.

\section{High risk of bias}

Any one of the following.

- Reason for missing outcome data likely to be related to true outcome, with either imbalance in numbers or reasons for missing data across intervention groups.

- For dichotomous outcome data, the proportion of missing outcomes compared with observed event risk enough to induce clinically relevant bias in intervention effect estimate.

- For continuous outcome data, plausible effect size (difference in means or standardised difference in means) among missing outcomes enough to induce clinically relevant bias in observed effect size.

- 'As-treated' analysis done with substantial departure of the intervention received from that assigned at randomisation.

- Potentially inappropriate application of simple imputation.

\section{Unclear}

Any one of the following.

- Insufficient reporting of attrition/exclusions to permit judgement of low or high risk of bias (e.g. number randomised not stated, no reasons for missing data provided).

- The study did not address this outcome. 


\section{Are reports of the study free of suggestion of selective outcome reporting?}

\section{Low risk of bias}

Any of the following.

- The study protocol is available and all of the study's pre-specified (primary and secondary) outcomes that are of interest in the review have been reported in the pre-specified way.

- The study protocol is not available but it is clear that the published reports include all expected outcomes, including those that were pre-specified (convincing text of this nature may be uncommon)

\section{High risk of bias}

Any one of the following.

- Not all of the study's pre-specified primary outcomes have been reported.

- One or more primary outcomes is reported using measurements, analysis methods or subsets of the data (e.g. subscales) that were not pre-specified.

- One or more reported primary outcomes were not pre-specified (unless clear justification for their reporting is provided, such as an unexpected adverse effect).

- One or more outcomes of interest in the review are reported incompletely so that they cannot be entered in a meta-analysis.

- The study report fails to include results for a key outcome that would be expected to have been reported for such a study.

\section{Unclear}

Insufficient information to permit judgement of low or high risk of bias. It is likely that the majority of studies will fall into this category.

\section{Other sources of potential bias}

\section{Low risk of bias}

The study appears to be free of other sources of bias.

\section{High risk of bias}

There is at least one important risk of bias. For example, the study:

- had a potential source of bias related to the specific study design used; or

- had extreme baseline imbalance; or

- has been claimed to have been fraudulent; or

- had some other problem.

\section{Unclear}

There may be a risk of bias, but there is either:

- insufficient information to assess whether an important risk of bias exists; or

- insufficient rationale or evidence that an identified problem will introduce bias.

\section{FEE D B A C K}

\section{Comment received 2 May 2002}

\section{Summary}

You seem to have restricted your review to Tinea pedis excluding Onchomycosis and LION study concerned mainly with Onchymocosis. However, what is the clinical or practical consideration to exclude onchomycosis when reviewing effective therapy for Tinea Pedis? Would the studies thus omitted not bring in important pieces of evidence to consider, as not cured infection of the toe nails will in the longer run lead to reinfection of the skin, perhaps after several months?

\section{Reply}

The LION study is not part of this review because the study compares two oral treatments for onychomycosis. As you observe our review is concerned with the effectiveness of oral treatments for fungal infections of the skin of the foot (Tinea pedis or athletes foot)and not oral treatments for fungal infections of the toenail (onychomycosis). The review considering oral treatments for onychomycosis is currently a published protocol within the Cochrane Library. 


\section{Contributors}

Comment sent by: Franz Piribauer, Consultant in EBM to Association of Sickfunds of Austria

Reply from: Sally Bell-Syer (lead review author)

Processed by: Urbà González, Cochrane Skin Group Criticisms Editor; Tina Leonard, Review Group Co-ordinator for the Cochrane Skin Group

\section{Comment received 10 November 2002}

\section{Summary}

You have chosen to divide evidence on treatments of fungal skin infections in at least three reviews (oral/foot, topical foot/nail, and rest of body). I can understand that, considering the amount of trials.

However, to make this division, you excluded trials that compare data for topical and oral treatment (e.g. Barnetson 1998 and Lynfeld 1974). I think this consequence is quite unfortunate, because these studies may be very helpful to provide evidence whether indeed oral treatment is more effective than local treatment, which is generally assumed, as you also do in your introduction. Would it not be informative to include these trials in some way or some trial?

\section{Reply}

Thank you for your comment. You correctly observe that the review of treatments for fungal infections of the foot has been approached in three parts by considering the effectiveness of oral treatments for skin infections of the foot, the effectiveness of oral treatments for toenail infections and thirdly the effectiveness of topical treatments for both skin and toenail infections. This decision was made by the review team and was considered to be the most appropriate way of answering the question of effectiveness. Another point taken into consideration was that oral treatments are obtainable by prescription only and therefore usually require a consultation with a healthcare professional, topical preparations on the other hand are available over the counter.

The inclusion criteria of the review on Oral Treatments for fungal infections of the skin of the foot, state that only oral comparisons will be included, therefore any trial that compared an oral drug to a topical preparation would be excluded from the review.

I understand your observation that including the evidence on comparisons of oral and topical treatments may add a further perspective to the review; indeed this would have resulted in a review with over 80 included trails. As I have explained the decision of the review team was that oral and topical agents would be considered in separate reviews.

Thank you for your interest.

(Note from the Criticisms Editor: the Skin group would consider registering a review comparing oral and topical treatments for fungal infections of the skin of the foot)

\section{Contributors}

Comment sent by: Sander Koning, GP

Reply from: Sally Bell-Syer (lead review author)

Processed by: Urbà González, Cochrane Skin Group Criticisms Editor; Tina Leonard, Review Group Co-ordinator for the Cochrane Skin Group

\section{WHAT'S NEW}

\begin{tabular}{|c|c|c|}
\hline Date & Event & Description \\
\hline 29 December 2014 & Review declared as stable & $\begin{array}{l}\text { There was } 1 \text { ongoing study listed in the review that the team had } \\
\text { tried to get data for, but the pharmaceutical company involved } \\
\text { did not respond. There was also one study awaiting classification } \\
\text { pending full text retrieval. A search of MEDLINE and PubMed in } \\
\text { October } 2013 \text { and October } 2014 \text { found one more ineligible study, } \\
\text { so we have marked this review as stable. Our Trials Search Co- } \\
\text { ordinator will run a new search towards the end of } 2015 \text { to re-as- } \\
\text { sess whether an update is needed. }\end{array}$ \\
\hline
\end{tabular}




\section{HISTORY}

Protocol first published: Issue 3, 1998

Review first published: Issue 2, 2002

\begin{tabular}{lll}
\hline Date & Event & Description \\
\hline 10 September 2012 & New search has been performed & $\begin{array}{l}\text { The review has been updated and a new review author has been } \\
\text { added. }\end{array}$ \\
\hline 10 September 2012 & $\begin{array}{l}\text { New citation required but conclusions } \\
\text { have not changed }\end{array}$ & $\begin{array}{l}\text { A new search has been conducted, and three new trials have } \\
\text { been included (Hoharitanon 2005; Smith 2001; Yamanchi 2000). } \\
\text { The conclusions have not changed. }\end{array}$ \\
\hline 5 November 2008 & Amended & Contact details updated \\
\hline 22 May 2008 & Amended & Converted to new review format. \\
\hline 5 December 2001 & $\begin{array}{l}\text { New citation required and conclusions } \\
\text { have changed }\end{array}$ & Substantive amendment \\
\hline
\end{tabular}

\section{CONTRIBUTIONS OF AUTHORS}

SB-S was the contact person with the editorial base, co-ordinated contributions from the co-authors, and wrote the final draft of the review. SB-S and SK screened papers against eligibility criteria.

SB-S and SK obtained data on ongoing and unpublished studies.

SB-S and SK appraised the quality of papers.

SB-S and SK extracted data for the review and sought additional information about papers.

SB-S and SK entered data into Review Manager 5.

SB-S and DT analysed and interpreted data.

DT commented on the clinical sections of the background and commented on the clinical comments of the referees.

SB-S responded to all the comments of the referees.

SB-S is the guarantor of the update.

\section{DECLARATIONSOF INTEREST}

The clinical referee, Professor Rod Hay, was the first author of the following two trials within this review (one excluded and one included):

- Hay RJ, McGregor JM, Wuite J, Ryattk KS, Ziegler C, Clayton YM. A comparison of 2 weeks terbinafine $250 \mathrm{mg} /$ day with 4 weeks of itraconazole 100mg/day in plantar - type tinea pedis. British Journal of Dermatology 1995;132 132:604-8.

- Hay RJ, Logan RA, Moore MK, Midgely G, Clayton YM. A comparative study of terbinafine versus griseofulvin in 'dry - type' dermatophyte infections. Journal of American Academy of Dermatology 1991;24(2 Pt 1):243-6.

\section{SOURCES OF SUPPORT}

\section{Internal sources}

- Department of Health Sciences, University of York, UK.

- The Wales Office for Research and Development for Health and Social Care, UK.

- University of Wales Institute, Cardiff, UK.

\section{External sources}

- No sources of support supplied

\section{DIFFERENCES BETWEEN PROTOCOLAND REVIEW}

There were no differences between the protocol and the original version of this review (Bell-Syer 2002). 
For this first update of the review, we undertook a 'Risk of bias' assessment following the guidance in the Cochrane Handbook for Systematic Reviews of Interventions (Higgins 2011).

\section{NOTES}

We have deemed this review as stable and no longer in need of updating. There was one ongoing study listed in the review that the team had tried to get data for, but the pharmaceutical company involved did not respond. There was also one study awaiting classification pending full text retrieval. A search of MEDLINE and PubMed in October 2013 and October 2014 found 1 more ineligible study. Our Trials Search Co-ordinator will run a new search towards the end of 2015 to re-assess whether an update is needed.

\section{N DEX TERMS}

\section{Medical Subject Headings (MeSH)}

Administration, Oral; Antifungal Agents [*administration \& dosage] [adverse effects]; Chronic Disease; Randomized Controlled Trials as Topic; Tinea Pedis [ ${ }^{\star}$ drug therapy]

\section{MeSH check words}

Humans 